\title{
Skin cancer therapeutics: nano-drug delivery vectors-present and beyond
}

\author{
Manisha Lalan ${ }^{*}$, Pranav Shah $^{2}$, Kalyani Barve ${ }^{3}$, Khushali Parekh$^{4}$, Tejal Mehta $^{4}$ and Priya Patel ${ }^{5}$
}

\begin{abstract}
Background: Skin cancers are among the widely prevalent forms of cancer worldwide. The increasing industrialization and accompanied environmental changes have further worsened the skin cancer statistics. The stern topical barrier although difficult to breach is a little compromised in pathologies like skin cancer. The therapeutic management of skin cancers has moved beyond chemotherapy and surgery.

Main body of the abstract: The quest for a magic bullet still prevails, but topical drug delivery has emerged as a perfect modality for localized self-application with minimal systemic ingress for the management of skin cancers. Advances in topical drug delivery as evidenced by the exploration of nanocarriers and newer technologies like microneedle-assisted/mediated therapeutics have revolutionized the paradigms of topical treatment. The engineered nanovectors have not only been given the liberty to experiment with a wide-array of drug carriers with very distinguishing characteristics but also endowed them with target specificity. The biologicals like nucleic acid-based approaches or skin penetrating peptide vectors are another promising area of skin cancer therapeutics which has demonstrated potential in research studies. In this review, a panoramic view is presented on the etiology, therapeutic options, and emerging drug delivery modalities for skin cancer.

Short conclusion: Nanocarriers have presented innumerable opportunities for interventions in skin cancer therapeutics. Challenge persists for the bench to bedside translation of these highly potential upcoming therapeutic strategies.
\end{abstract}

Keywords: Skin cancer, Nanovectors, Topical therapy

\section{Background}

Topical delivery has been a center of attention for pharmaceutical, nutraceutical as well as cosmeceutical industries. Particularly, from the medical perspective, topical delivery provides a suitable alternative for localized self-application for the treatment of skin diseases such as dermatitis, rosacea, psoriasis. This is important as the treatment remains localized to the affected area of the skin and poses only minimal to negligible systemic toxicities [1]. Moreover, a large variety of nanoparticulate systems such as liposomes, micelles, polymeric

\footnotetext{
${ }^{*}$ Correspondence: manisha_lalan79@yahoo.co.in

${ }^{1}$ Babaria Institute of Pharmacy, BITS Edu Campus, NH\#8, Varnama,

Vadodara, Gujarat 391240, India

Full list of author information is available at the end of the article
}

nanoparticles, and strategies such as the use of skin penetrating peptides, skin permeation enhancers, or microneedle systems are available to act as drug carriers to address issues related to drug toxicity, skin irritation, limited permeation of drugs, and so on $[1,2]$.

Another disease area that has seen growth in the local application of therapeutics is skin cancer which happens to be the most common cancer with one of every three cancer diagnoses being a skin cancer as per WHO [3]. Skin cancer is the most prevalent form of cancer in the US as per Centers for Disease Control and Prevention [4] with an incidence rate of one in five Americans developing skin cancer during their life [3]. Skin cancer is broadly classified into non-melanoma skin cancer which includes basal cell carcinoma and squamous cell carcinoma and melanomas [5]. As per WHO, the 
estimated crude rate of incidence of melanoma worldwide in 2020 is 4.2 [6].

The major cause of skin cancer development is exposure to UV radiation [7-9]. Hence, the majority of the strategies directed towards skin cancer are preventive strategies to reduce exposure of skin cells to UV radiation. However, once the cancer cells have been developed into tumors, treatment options available are surgical removal of tumors (cryosurgery, excision, or others) or therapy with topical 5-FU, immunotherapy (intravenous Immunoglobulins such as Pembrolizumab, Nivolumab, Ipilimumab), or targeted oral small molecule therapy (Vismodegib, Sonidegib) and novel therapy using oncolytic virus such as Talimogene Laherparepvec $\left(\right.$ Imlygic $\left.^{\circledR}\right)[10,11]$.

Advancements in topical delivery of drugs have recently given pace to research on the delivery of drugs for chemoprevention and treatment of skin cancers. Varieties of nanocarrier systems of chemopreventive agents are available which prevent the inception of skin cancers at their root causes. This includes, for example, nanoparticulate UV-B absorbing agents (titanium dioxide, zinc oxide etc.), anti-oxidants or ROS scavenging agents (resveratrol, quercetin, carnosol etc.) [12-14] or cyclo-oxygenase-2 (COX-2) inhibitors (celecoxib, etodolac) [15]. Of particular importance to note is the use of UV-B absorbing agents which do not require to be absorbed in the skin for their activity, however, other agents that prevent reactive oxygen species (ROS) generation post-UV-B exposure and COX-2 inhibitors work at the cellular level and hence require better absorption in the skin layers and cells for their activity. Some agents such as carnosol have overlapping mechanisms i.e. absorption with UV-B spectrum and also have the ability to scavenge ROS and hence provide dual activity [13]. Among these agents, UV-B absorbing agents can protect against actinic keratosis and squamous cell carcinoma; however, supporting research on protection against basal cell carcinoma and malignant melanoma is inconclusive [16].

Specifically, when it comes to treating skin cancers, localized delivery of cytotoxic drugs is of great benefit as topical application avoids/limits systemic toxicity of cytotoxicity of drugs which reduce patient compliance and greatly limit the quality of life of cancer afflicted people. However, this also poses a great challenge of bypassing the Stratum corneum and epidermal skin barriers which are designed to be the first line of defense of the body from xenomaterials and to hold moisture in dermal and subdermal tissues to prevent skin from drying out $[17,18]$.
The current manuscript reviews the pathological alterations in the skin due to cancer, unmet therapeutic needs for skin cancer treatment and possible solutions offered by nanoparticulate drug delivery systems for chemoprevention as well as therapeutic management. Also, discussed is the detailed account of various challenges and strategies to overcome those challenges using nanocarriers for topical treatment of skin cancer. Lastly, novel biological approaches such as the use of nucleic acid-based carriers (framework nucleic acids-FNAs, spherical nucleic acids-SNAs) and skin penetrating peptides are discussed.

\section{Main text}

\section{Skin anatomy and physiology}

In brief, the skin has three layers namely epidermis, dermis (reticular and papillary), and subcutaneous layer also known as hypodermis. The epidermis comprises four basic layers starting from the deepest to the superficial: Stratum basale, Stratum spinosum, Stratum granulosum, and Stratum corneum. The deepest layer comprises dividing keratinocytes which push the cells on the outer side. As the cells move out they lose their nuclei and secrete lipids in the intercellular spaces; by the time the cells reach the outermost surface, they are dead and form a layer of laminated and loosely attached keratinocytes. The Stratumbasale also houses other cells like melanocytes, Merkel cells, and the cells of Langerhans. The dermis comprises cellular elements like fibroblasts, hair follicles, sebaceous glands, apocrine glands, eccrine glands as well as blood vessels and nerves; acellular elements like fibers and ground substance. There are two lymphatic plexuses namely superficial lymphatic plexus and large lymphatic vessels found around the blood vessels of the upper and lower layer of the dermis, respectively. The subcutaneous tissue is composed of connective tissue and also contains fats, blood vessels and nerves.

The epidermis acts as a barrier for several pathogens and protects the underlying layers. The dermis supports and nourishes the epidermis, whereas the subcutaneous layer stores fat, regulates body temperature, and also acts as a shock absorber [19].

\section{Skin cancer}

\section{(a) Etiology}

There are two main types of skin cancer:

1. Non-melanoma that includes (a) Basal cell carcinoma is a malignant neoplasm derived from basal cells and commonly occurs on the head and neck mainly 
due to alterations in the hedgehog pathway and (b) Squamous cell carcinoma is a malignant tumor of keratinocytes that invades the dermis mainly caused due to genotoxic stress leading to DNA damage.

2. Melanoma: Malignant melanoma is the malignancy of the melanocytes and can occur in any tissues harboring these cells. This is caused either due to exposure to harmful ultraviolet radiation or due to mutations in several genes.

The less common cancer types include atypical fibroxanthoma, cancer of skin glands, Kaposi sarcoma, Merkel cell carcinoma, Paget's disease of the nipple, cutaneous T-cell lymphoma, sebaceous carcinoma, dermatofibrosarcoma protuberans [20, 21]. Figure 1 shows the classification of skin cancer.

The risk factors are of two types namely (1) Constitutional factors which include phototype, skin, and eye color, number of melanocytic nevi, presence of dysplastic nevi, individual or family history of skin cancer and (2) Environmental risk factors which include type and degree of cumulative sun exposure, history of sunburn, and sun protection behavior of skin [22, 23]. Skin cancer is mainly caused due to carcinogens like UV radiations, chemicals, viruses, or mutations in the genes.

\section{UV radiations}

Exposure to UV rays is considered one of the main factors contributing to skin tumorigenesis. The UV rays initiate a series of events starting from the production of reactive oxygen species leading to an inflammatory response that alters the cell structure and function. NLRP1 inflammasomes are the ones involved in susceptibility to skin cancer [24]. UV radiations are easily absorbed by the many chromophores in our skin such as melanin, proteins, lipids, and DNA. The DNA of keratinocytes, in particular, can absorb these harmful radiations and form cyclobutane pyrimidine dimers and 6,4 photoproducts, which in turn leads to immunosuppression. The same radiations can isomerize another chromophore-trans-urocanic acid, activating the $5 \mathrm{HT} 2 \mathrm{~A}$ receptor and causing immunosuppression. Thus, UV rays can cause immunosuppression and mutations resulting in tumors. The UV radiations also inhibit the cells residing in the skin such as the mast cells, T cells (cytotoxic and memory), and activate lymphocytes ( $\mathrm{T}$ and $\mathrm{B}$ ) and natural killer cells. They cause migration of Langerhans cells to the lymph nodes thereby

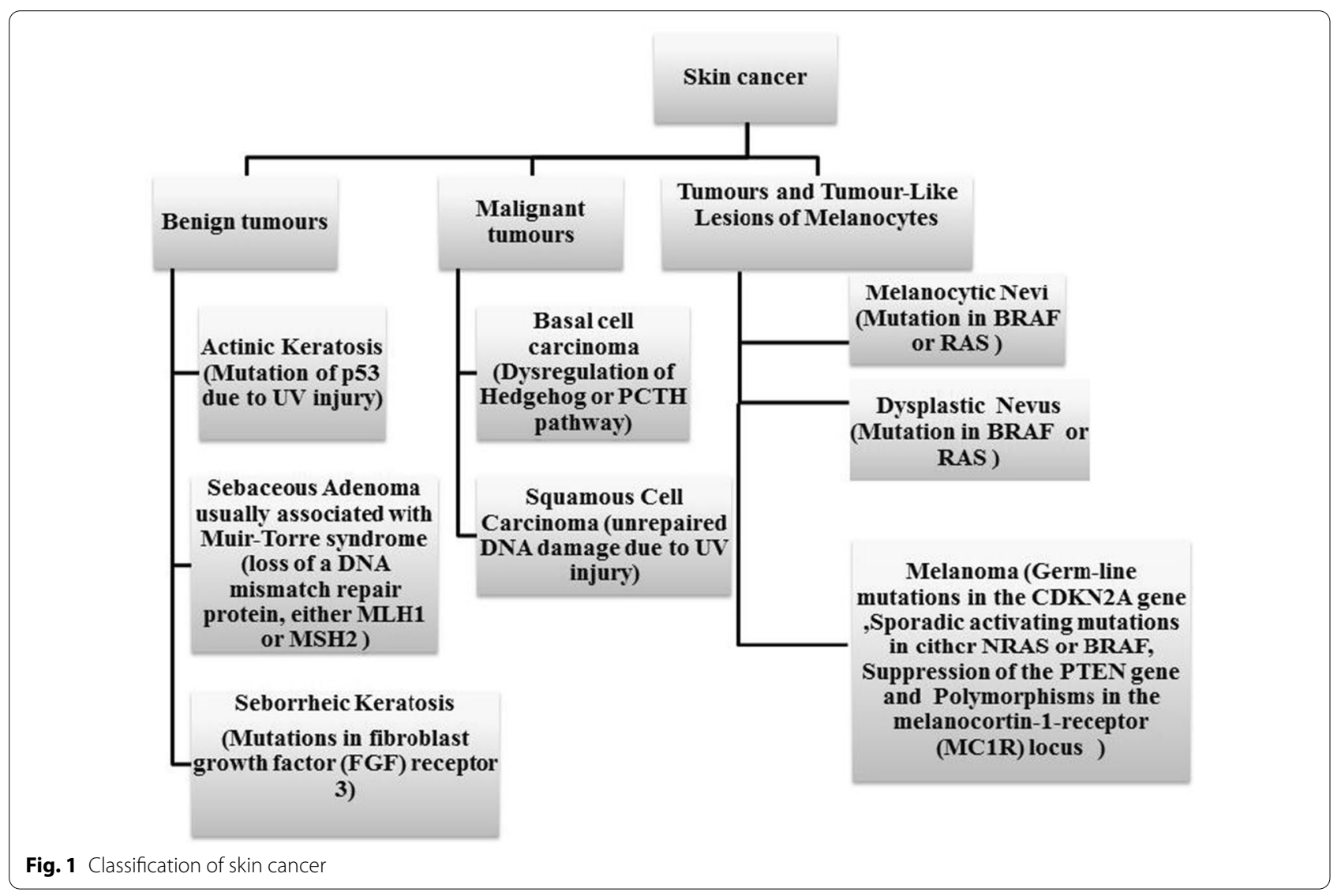


depleting the skin of its defenses making it vulnerable to cancerous lesions [25].

UV rays comprise UV-A and UV-B radiations. Though UV-B is considered more harmful, UVA is also not without adverse effects. UV-A reaches deep down into the dermis, causing carcinogenesis of the stem cells of the skin. UV-A can also cause DNA damage by producing free radicals and damaging the cell membrane in turn causing skin cancer. UV-B gets absorbed by proteins on the epidermis and inflicts DNA damage in the cells. UV-B also causes oxidative damage to the skin. UVB radiations further disrupt the regulatory proteins, anti-apoptotic proteins, pro-apoptotic proteins, transcription factors, protein kinases, inflammatory enzymes, and growth factors which in turn disturb the cell cycle. It further causes mutations in various tumor suppressor genes and oncogenes. These effects together lead to uncontrolled mitosis of keratinocytes and initiate skin cancer upon UV exposure [26].

\section{Chemicals}

Polycyclic aromatic hydrocarbons (PAH) and arsenic are the most common chemical carcinogens for skin cancer. Workers in industries that produce $\mathrm{PAH}$ such as coal production plants, aluminum production plants, steel, and iron foundries are at a greater danger of suffering from skin cancer. Similarly, agricultural workers, miners, and people living in rural areas drinking untreated water are exposed to arsenic and are potentially at risk of skin cancer [26].

\section{Viruses}

Viruses act by stimulating cancer-promoting genes in keratinocytes or they might act as oncogenes and lead to cancer. The common viruses are (i) Human papillomavirus (HPV) linked to squamous cell carcinoma (SCC) (ii) Herpes virus associated with Kaposi's sarcoma; and (iii) human T-cell leukemia virus type 1 (HTLV-1) which majorly causes adult T-cell leukemia [26].

To summarize, all the above agents lead to skin cancer by causing unregulated proliferation of cells, DNA damage, inflammation, immunosuppression, angiogenesis, and inhibiting apoptosis.

\section{Genetic factors}

Most skin cancers occur due to genetic abnormalities. Certain mutations in cyclin-dependent kinase inhibitor $2 \mathrm{~A}$ were the most frequent genetic abnormalities detected. Polymorphism in antioxidant enzymes such as glutathione S-transferase, which fights against the UVR induced free radical damage, can predispose patients to skin cancer [27]. Mutations of melanoma susceptibility gene p16, Ras oncogene, tumor suppressor gene p53,
BRM tumor suppressor gene, PTCH1 tumor suppressor gene, CDKN2A gene, BRAF gene, C-KIT (receptor tyrosine kinase) and mutations at any point in the MAPK and PI3K-AKT pathways are responsible for non-familial cases of skin cancer [25].

Patients with family cancer syndromes like familial retinoblastoma, Li-Fraumeni cancer syndrome and Lynch syndrome type II, also show a higher risk of developing melanoma. Even pigmentation is related to the risk of skin cancer. It is a phenotypic trait with high heritability. Single nucleotide polymorphism in pigmentation genes related to skin cancer risk has been identified $[28,29]$. Accordingly, the risk of developing skin cancer increases in people with certain pigmentary characteristics such as fair skin, numerous freckles, light colored eyes and hair, sun sensitivity, and an inability to $\tan [23]$.

\section{(b)Pathophysiologic alterations in skin cancer}

Metastasis in BCC (basal cell carcinoma) is very uncommon. It brings about superficial changes in the skin structure. BCC can cause an uneven patch or a bump on the skin. Atrophic scar formation is visible as cancer starts spreading peripherally. As it starts invading the inner tissues, ulcerations might be seen. Sometimes there may be melanin deposition in these tumors. Superficial BCCs occur in multiple numbers, especially on the covered body parts. It is seen as flat red scaly patches and is frequently characterized by traumatic bleeding, crust formation, erosion, ulceration, and scar formation. As opposed to BCC, SCC can metastasize to the regional lymph nodes and also to the nearby organs and hence is more dangerous. It appears as an ulcer with a wide hardened border or as papules, nodules; hyperkeratotic, or erosive skin lesions. The tumor may invade the underlying tissue [30] Melanoma skin lesions are characterized by $\mathrm{ABCDE}$ - A-asymmetry, B- irregular border, C-color which is not uniform and may vary from black to brown, D-diameter more than $6 \mathrm{~mm}$ and E- evolution, elevation, and enlargement of the lesion. The lesion may be accompanied by inflammation, hyperkeratosis, or bleeding [19].

(iii) Therapeutic management paradigms

The therapies for skin cancers vary as per the type of cancer from surgical excision, radiation therapy to chemotherapy. Despite newer techniques available, surgery remains the cornerstone to treat any type of skin cancer. There are three types of surgeries performed: excision, Moh's micrographic surgery, and Curettage and electrodessication [31]. However, where surgical treatment is not possible or for low-risk tumors or where the patient is unwilling to undergo surgery; topical or systemic chemotherapy, radiation therapy, cryosurgery, or photodynamic 
therapy (PDT) are alternatives available. Cryosurgery is advocated when other therapies are contraindicated or not practical, though it has a recurrence rate of $39 \%$ after 2 years. Radiation therapy is of three types and includes superficial radiation therapy, isotope-based brachytherapy, and external electron beam radiation. Radiation treatment is given over several weeks in small doses. Post radiation notable side effects comprise acute radiationrelated skin toxicity, potential radiation-related changes to cellular structures, and the extra difficulty of handling recurrences within the radiation field. Late adverse events can cause alopecia, cartilage necrosis, and skin pigmentary changes in addition to the chances of secondary malignancy. PDT is used to treat small nodular BCCs. It makes use of three variables: photosensitizing agents like 5-aminolevulinic acid and its methylated derivative, oxygen and light. In this therapy, exposure to light activates the photosensitizing agent which in the presence of molecular oxygen generates reactive oxygen species that target the tumor cells, initiate an immune and inflammatory response that can keep a check on tumor cells for a long time. It can be combined with the other treatments and gives excellent cosmetic results providing higher satisfaction to patients. Post-treatment adverse events include photosensitivity and thus, light avoidance and photoprotection for $48 \mathrm{~h}$ is warranted. Erythema, edema, tenderness, and, occasionally, crust or erosions might occur [32-34].

The current management of different types of skin cancer is as mentioned in Table 1.
Management with chemotherapeutic agents is either secondary or needs to be given in combination. BRAF inhibitors need to be given along with other targeted chemotherapeutic agents, since single agent treatment may lead to multiple mutations in the tumor reactivating mutated MAP kinase pathway causing treatment resistance [35]. Dabrafenib and trametinib is the most widely used combination. Ipilimumab and nivolumab; encorafenib plus binimetinib combinations are also used, and they have a longer duration of action as compared to debrafenib and trametinib.

Surgical excision and radiotherapy are the treatment options available for all other minor carcinoma like sebaceous carcinoma, eccrine porocarcinoma, Merkel cell carcinoma, and atypical fibroxanthoma [36]. Retinoids are used as chemopreventive agents for NMSC (nonmelanoma skin cancer). However, it is associated with dryness of lips, mucous membranes and skin, hair loss, bone toxicity and hepatotoxicity. Oral retinoids are also teratogenic and are used only in specific high-risk patients. Other chemopreventive agents including Nicotinamide, NSAIDs, Difluoromethylornithine, Vitamin D, polyphenols, and retinoids are used for NMSC [25]. However, the efficacy of these agents is yet to be firmly established.

(iv) Therapeutic challenges and unmet therapeutic needs

In spite of a wide array of therapeutic options available for different types of skin cancer, some of the tumors

Table 1 Management of skin cancer

\begin{tabular}{|c|c|c|c|c|}
\hline Type of cancer & Type of surgery & Medicines applied topically & Medicines given orally & Others \\
\hline Basal cell carcinoma & $\begin{array}{l}\text { Mohs micrographic surgery } \\
\text { (MMS) }\end{array}$ & Imiquimod, Ingenol mebutate & Vismodegib & Radiation therapy, PDT \\
\hline Squamous cell carcinoma & $\begin{array}{l}\text { Standard excision, Mohs } \\
\text { micrographic surgery, Curet- } \\
\text { tage and electrodesiccation, } \\
\text { Cryosurgery }\end{array}$ & $\begin{array}{l}\text { Imiquimoid, Diclofenac } \\
\text { gel (3\%), 5-Fluorouracil, } \\
\text { Cetuximab }\end{array}$ & - & PDT Radiotherapy \\
\hline Melanoma & $\begin{array}{l}\text { Surgical excision, sentinel lymph } \\
\text { node biopsy }\end{array}$ & Imiquimod & $\begin{array}{l}\text { BRAF kinase Inhibitors- } \\
\text { vemurafenib and dabrafenib, } \\
\text { encorfenib; NRAS Inhibitors- } \\
\text { Binimetinib; CKIT Inhibitors- } \\
\text { imitinib and nilotinib and MEK } \\
\text { Inhibitors - trametinib and } \\
\text { cobimetinib. Immunothera- } \\
\text { pies for melanoma include } \\
\text { Cytotoxic T-lymphocyte Anti- } \\
\text { gen } 4 \text { Inhibitors_-Ipilimumab; } \\
\text { Programmed Cell Death } \\
\text { Receptor } 1 \text { Inhibitors-Pem- } \\
\text { brolizumab and Nivolumab } \\
\text { and anti-PDL1 (programmed } \\
\text { death ligand 1)-Atezolizumab. } \\
\text { If these fail Temozolomide } \\
\text { and Dacarbazine }\end{array}$ & Radiation therapy \\
\hline
\end{tabular}


do not respond as expected leading to treatment failure. Resistance to treatment is the primary reason for this phenomenon. The internal and external environment of the tumor decides the resistance pattern against every therapy. The intrinsic factors include mutations in the genes such as tumor suppressor gene p53, PTCH1 gene, cyclin D1 overexpression, alteration of the Wnt/ $\beta$-catenin signaling pathway, overexpression of $\mathrm{P}$-gp glycoproteins responsible for the transport of drug out of the cell. Reduced immune effector mechanism and autophagy are some additional ways of resistance development. The external environment is responsible for the acquired resistance of tumor cells. These may include the factors in the tumor environment and possible mutations arising during the treatment. Adaptive responses such as activation of compensatory signaling pathways in the tumor cells, cross-resistance, and heterogeneity of the tumor type with different phenotypic, genotypic, and epigenetic characteristics additionally contribute to development of resistance.

Resistance develops to PDT due to thickness of the tumor, presence of melanin pigments, more amount of collagen in the tumor, infiltrative growth tissue, and ulceration. PI3 K/Akt and the MAPK/ERK pathways implicated in the proliferation, survival, and inhibition of apoptosis also is crucially involved in the development of resistance to PDT. Constitutive activation of EGFR and STAT3 which are essential in the transmission of growth signals is known to give rise to resistance against radiation therapy [36].

Resistance also develops against chemotherapeutic agents. Slow-growing tumors in SCCs are resistant to the intralesional methotrexate therapy. PTCH gene mutation, SMO mutations, mutations in the target $\mathrm{HH}$ gene cyclin D1, and a compensatory upregulation of IGF-1R/ PI3 $\mathrm{K}$ are found to be responsible for vismodegib resistance. Resistance can also develop to systemic Cetuximab due to K-RAS mutation, constitutive activation of EGFR, EGFR-dependent nuclear translocation of Src, PTEN instability, AKT hyperactivation, upregulated expression of EGFR ligands, and positive regulation of EGFR, HER2, and HER3.

Polymorphism in dihydropyrimidine dehydrogenase, an enzyme responsible for metabolism of 5-FU and overexpression of Bag-1 and Hsp70 are responsible for the resistance towards 5 -FU. Similarly, polymorphisms in the TLR7 gene and reduced TNF- $\alpha$ levels are believed to be responsible for resistance toward imiquimod. High levels of intracellular calcium that are present in the differentiated keratinocytes, T-cell deficiency, or polymorph neutrophil deficiency are some possible mechanism of resistance towards Ingenol mebutate [37]. Having an understanding of resistance mechanisms for various therapies, it becomes easier to devise ways to overcome the resistance. A few examples are miRNAs which are reported to reverse drug resistance and restore drug sensitivity and Mibefradil; a calcium channel blocker is found to increase sensitivity to MAPK inhibitors in melanoma [38].

Though resistance can be overcome by above-mentioned options, serious adverse reactions of chemotherapeutics (Table 2) are still a problem. Immune checkpoint inhibitors (CTLA4- Ipilimumab, programmed cell death 1 (PD-1)-pembrolizumab and Nivolumab or Programmed cell death ligand 1 (PD-L1)Atezolizumab) cause some of the serious autoimmunerelated skin condition, unmasking or worsening of atopic dermatitis, psoriasis or sarcoidosis. BRAF1 inhibitors (encorfenib, vemurafenib, and dabrafenib) cause UV-Ainduced phototoxicity and cutaneous toxicity. Some of the agents do not have favorable pharmacokinetics. Thus, overcoming resistance, suppressing adverse reactions and improving pharmacokinetic parameters of anti-cancer drugs, developing theranostic nanocarriers, are some of the unmet therapeutic needs. To satisfy these needs, we have to find novel ways to deliver the existing drugs either as single agents or as an adjuvant with other drugs and along with diagnostic agents. Nanotechnology offers vistas and possibilities for addressing the challenges and unmet needs by modifying pharmacokinetics, reducing the adverse events by dose reduction, and better cellular permeability for the therapeutic molecules. For example, electrochemotherapy is an alternative to enhance the permeability of the skin and deliver chemotherapeutic agents like cisplatin and bleomycin into the cancer cells [21]. Biologicals, nucleic acid-based therapies and phytochemicals could be a game changer in the future.

\section{Nano-formulations for skin cancer}

Nanotechnology is commonly referred to any material, technique, or equipment that functions at the nanoscale. The amalgamation of various therapeutic, diagnostic, and targeting agents into nanocarrier was well developed during the past two decades, which has enabled better detection, timely prevention, and more effective treatment of oncological diseases. Elaborate studies have gone into developing nanoformulations (NFs) for topical delivery; however, no commendable progress has been made in translating them from bench to bedside in treating skin cancers. Figure 2 is a graphical representation of the various types of skin cancers and the use of nanoparticles in the treatment of the disease along with their benefits [67].

Nanoformulations offer multifarious benefits in the management of skin cancer. They can enhance the solubility of poorly water-soluble drugs, half-life, and 


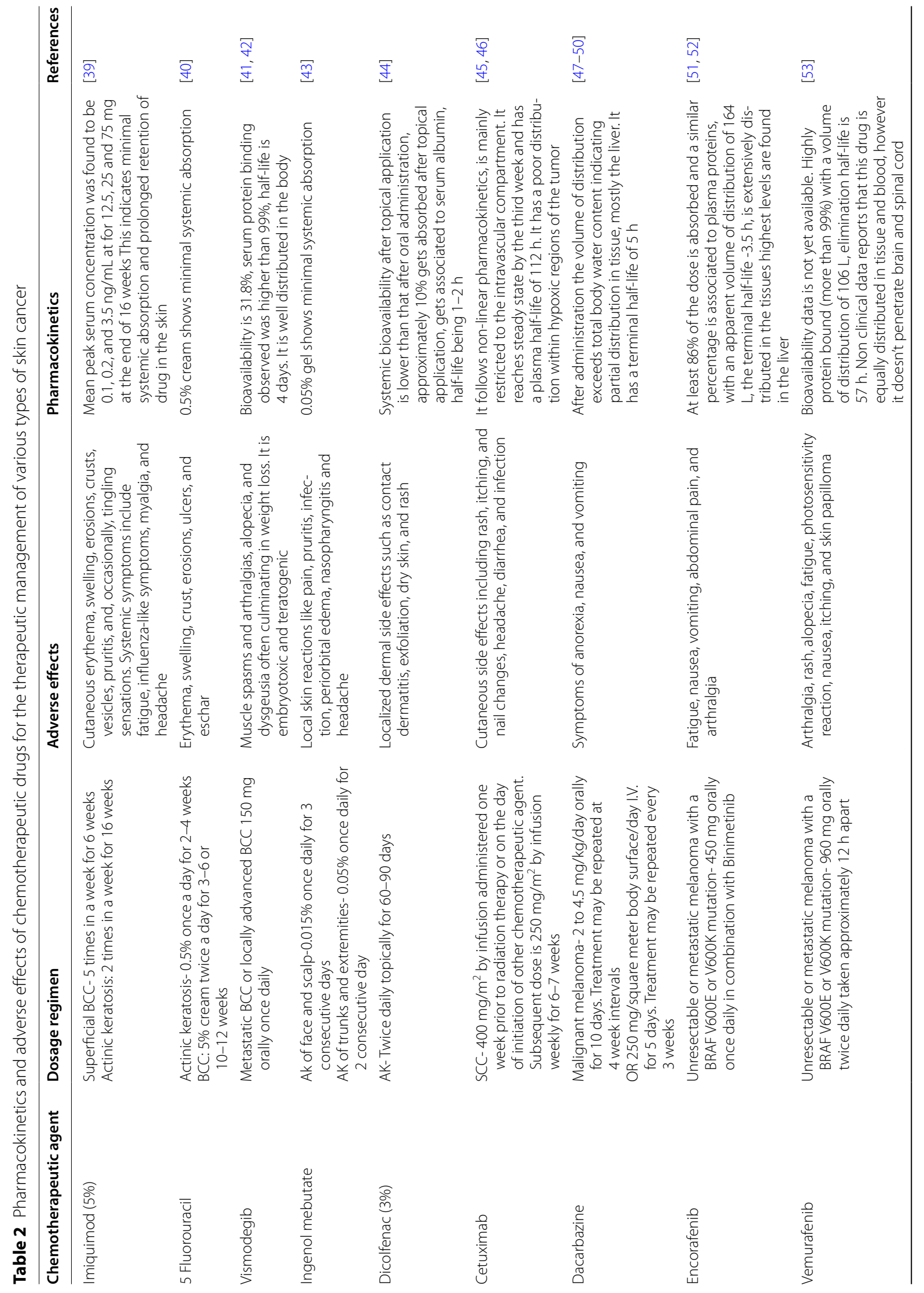




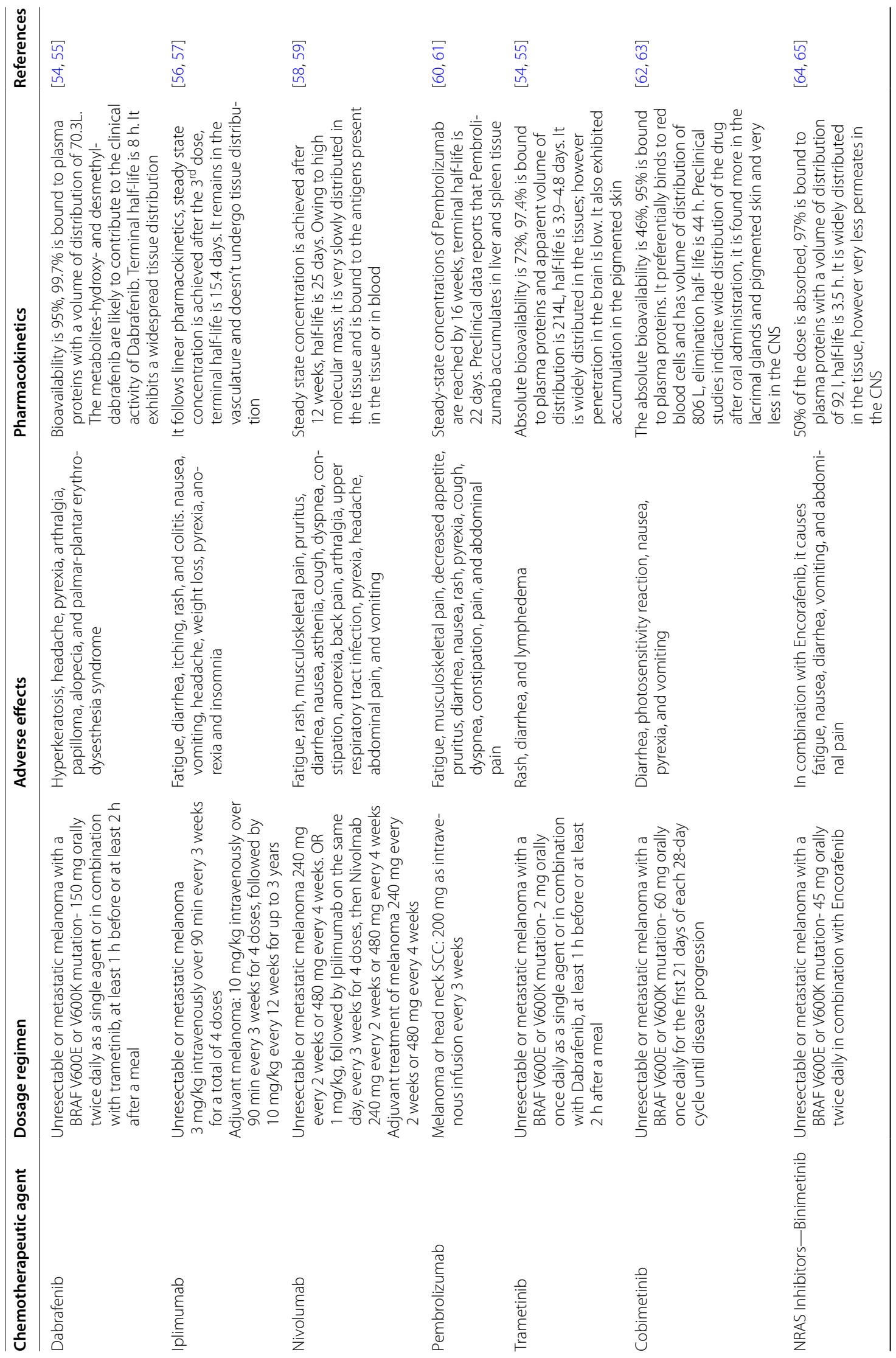




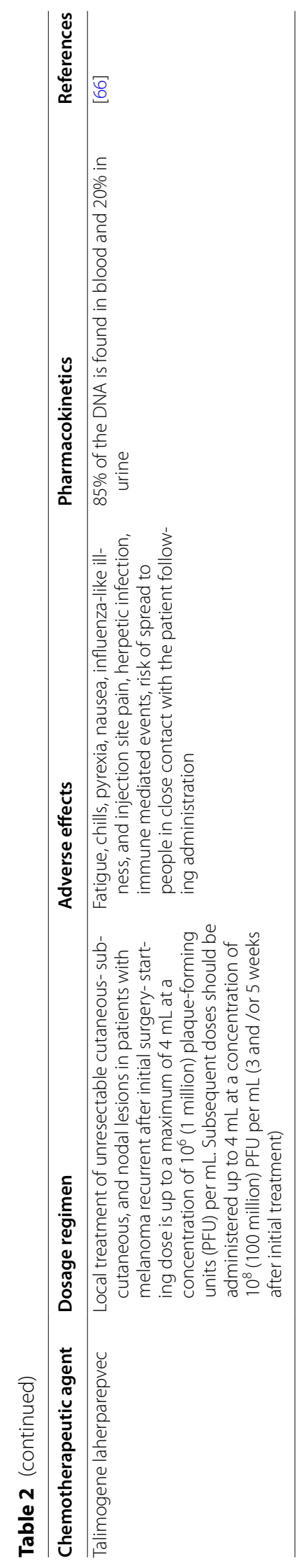




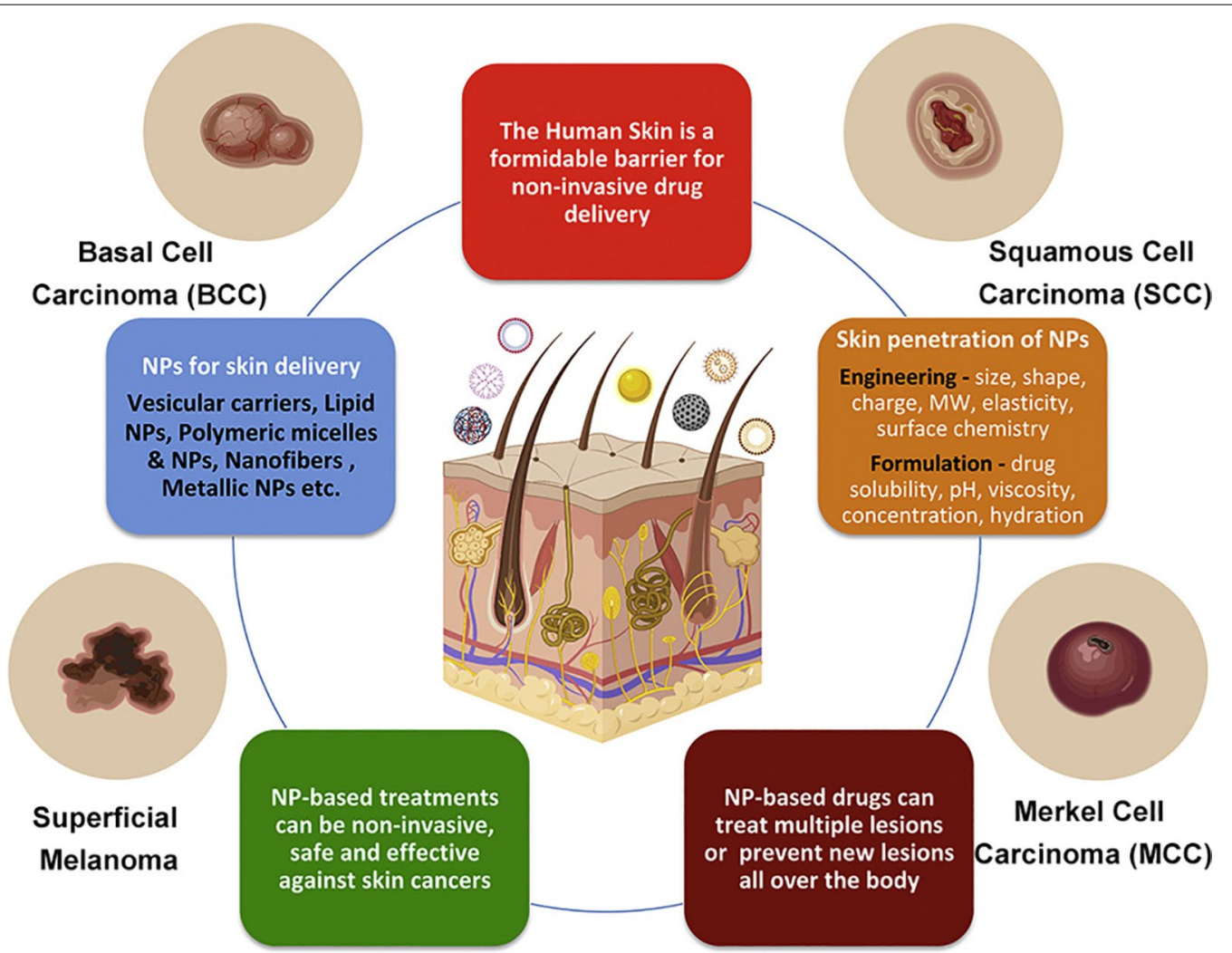

Fig. 2 Types of skin cancers and use of nanoparticles in the treatment of the disease. Reproduced with permission from Krishnan and Mitragotri [67]

pharmacokinetic parameters of the drug to overcome the drug resistance. Drug incorporation in nanocarriers can help in leveraging their biomimetic properties to improve bioavailability. Further, they will be preferentially accumulated in tumors through the enhanced permeability and retention and surface modification strategies can endow them with specific targeting abilities. Their benefits can be augmented when used in combination with physical permeation enhancement techniques.

Most of the nanoformulations for skin cancer are either in the development phase or clinical trial phase. The mechanistic understanding of their permeation characteristics and pharmacokinetics will help in the better design of such products. As is the case with all nanoformulation-based products, scale up issues, toxicology of the components, and batch-to-batch reproducibility are their prospects of successful bedside translation [68].

\section{Types of nano-formulations and their common properties}

Nanoformulations offer unique avenues for the management of skin diseases. The barrier function of the skin presents a formidable challenge for nanoparticles to permeate into the tissue, although the barrier is partially breached in injuries or inflammatory episodes, as in the case of skin cancer. This can be leveraged to increase the penetration of NFs. They can be mainly divided into 3 categories, viz. Particulate NFs, vesicular NFs, and colloidal NFs. Some of the widely used formulations are discussed below:

(a) Particulate nanoformulations

(b) Lipid-based nanoparticles

\section{Solid lipid nanoparticles (SLNs)}

The merits of liposome and polymeric nanoparticles are combined in the new generation of delivery systems known as Solid Lipid Nanoparticles (SLNs) [69]. SLNs can offer multiple advantages, such as targeting to site of action, physical stability, the plausibility of controlled release of both lipophilic and hydrophilic drugs, protection of labile drugs, low cost, ease of preparation. Similar to liposomes, SLNs can be formulated avoiding the use of toxic solvents, and hence, SLNs are approved for pharmacological applications in humans. Here, the use of toxic chemicals is minimized which defends chemical degradation of the drug and allows sustained release of the drug with adequate physical stability [70]. SLNs 
have few drawbacks like variable capacity of drug encapsulation and drug leakage from the matrix upon storage [71]. However, despite a few limitations, SLNs are being explored widely as drug delivery platforms in the treatment of life-threatening diseases like cancer due to their potential advantages as mentioned above [72, 73].

Tupal et al. investigated the topical delivery of Doxorubicin (Dox) loaded SLNs for skin cancer. They formulated the SLNs with the objective that Dox-loaded SLNs would decrease the systemic side effects of Dox along with improvement in the therapeutic effectiveness. They achieved promising results for dermal delivery of Doxloaded SLNs with supporting in vitro and in vivo data. It was observed that SLN suspension enhanced drug permeability, improved cellular uptake, and reduced cell viability with change in the concentration. Results of histological evaluation reveal considerable improvement in tumor tissue restriction and no damage to skin surface due to free Dox in the administration of Dox-SLN. They also suggested the need for further studies like stability studies and in vitro cytotoxicity with Dox-SLN on the various organs other than the targeted ones, to exploit the use of lipid-based carrier systems for the treatment of melanoma [74].

Cassano et al. developed and evaluated $\alpha$-tocopheryl linolenate-based solid lipid nanoparticles along with its antioxidant activity study. They successfully incorporated omega-3 $\alpha$-linolenic acid (an advantageous substance in the therapeutic management of skin cancer) into SLNs. The attained results indicated that the $\alpha$-tocopherol, linked to $\alpha$-linolenic acid by ester bond, is mainly responsible for the maintenance of excellent antioxidant activity. $77 \%$ drug encapsulation was achieved with the polydispersity index of 0.198 indicating a good homogeneity. Furthermore, the cytotoxic activity of the SLNs was tested against human melanoma cancer cell line using two nanoformulations (empty nanoparticles and SLNs loaded with $\alpha$-linolenic acid) and they observed the IC50 values of 0.82 and $2.44 \mu \mathrm{g} / \mathrm{ml}$, respectively. Statistical analyses (Bonferroni test) indicated a significant difference amidst these exceptional results and the cytotoxic effect on melanoma cell line. SLN loaded with $\alpha$-linolenic acid and $\alpha$-tocopherol showed high biological activity and more effectiveness than $\alpha$-linolenic acid and $\alpha$-tocopherol alone. The results confirmed the capability of SLNs in protecting unstable molecules from degradation because of oxidative stress [75].

T. Geetha et al. developed sesamol-loaded solid lipid nanoparticles for the treatment of melanoma. Sesamol has marked antioxidant properties which may be useful to fight against skin cancers. The study confirmed the apoptotic nature of sesamol using in vitro anti-proliferative techniques like MTT assay and DNA fragmentation studies in HL60 cell lines. Sesamol has satisfactory physicochemical properties which enable its prompt absorption with higher flux. The same was confirmed by performing ex vivo skin permeation and retention studies. Hence, it was assumed that sesamol enters systemic circulation immediately without any lag time after topical application. Markedly high flux $(38.92 \pm 0.62 \mathrm{mg} /$ sq.cm/h), and minimal retention in the skin tissue were observed. In vivo studies were performed using TPAinduced and benzo(a)pyrene initiated tumor production (ROS mediated) in a mouse model which confirmed that incorporation of sesamol into SLNs shows low skin retention (less than $7 \%$ at $4 \mathrm{~h}$ ) as compared to the sesamol alone. When sesamol was incorporated in the ointment base, it showed significant lag time with the release of a small amount of sesamol ( $99.32 \mathrm{mg}$ at $2 \mathrm{~h}$ ). Thus, by incorporation of sesamol into SLN helped in enhancing its local bioavailability at the site of application and achieving the desired anticancer effect. In addition, the study also concluded that S-SLNs were useful as therapeutic agents in the treatment of cancer [76].

Gupta et al. developed Curcumin solid lipid nanoparticles using a high-pressure hot homogenization technique. The developed formulation exhibited a significant augmentation of solubility and drug loading. SLNs exhibited zero-order drug release and enhanced stability. The authors reported 69.78 folds and 9 folds higher oral bioavailability as compared to free Curcumin and marketed formulation $\left(\mathrm{CurcuWIN}^{\circledR}\right)$. The results ensure the efficacy of Curcumin solid lipid nanoparticles in treating cancer and other inflammatory diseases [77]

The nanometric size and complexity of colloidal populations are one of the reasons why polymorphic transitions have not been deciphered precisely. However advanced biophysical techniques such as cryo- and freeze-fracture transmission electron microscopy, SAXS, and SANS are being applied to study SLN structures. The prospects for this type of delivery system indicate surface functionality and improved targeting as their mechanism for overcoming drug resistance is highly generic [78].

\section{Nanostructured lipid carriers (NLCs)}

Unlike SLNs, Nanostructured Lipid Carriers (NLCs) are the second generation of lipid nanoparticles. However, NLCs have a highly unordered structure due to the mixture of solid and liquid lipids which enhances drug loading capacity with reduction of water content in the nanocarrier in comparison to SLNs. They remain solid at room temperature and physiological temperature also [79]. NLCs can be manufactured at low cost and technology transfer to a large scale is also easy. Hence, it is endorsed to explore NLCs for drug delivery through oral, 
pulmonary, IV injection, nose-to brain, dermal and ocular routes.

Almousallam et al. studied Dacarbazine (DAC) loaded nanostructured lipid carrier for improvement in the drug solubility and prolonged drug release. Precirol ATO5 and isopropyl myristate were used as lipids for the synthesis of blank and DAC encapsulated NLCs. Tocopheryl polyethylene glycol succinate, soybean lecithin, and Kolliphor P 188 were used as co-surfactants. High shear dispersion followed by solidification of $\mathrm{o} / \mathrm{w}$ emulsion method was used to achieve controlled sized NLCs. An optimized batch of DAC encapsulated NLC had a particle size of $155 \pm 10 \mathrm{~nm}$, PDI of $0.2 \pm 0.01$, and zeta potential of $-43.4 \pm 2 \mathrm{mV}$. $98.5 \%$ drug encapsulation and $14 \%$ of drug loading were achieved. A biphasic drug release pattern was observed, as $50 \%$ of the drug was available in the first $2 \mathrm{~h}$ where the remaining $50 \%$ was released in a sustained manner for $30 \mathrm{~h}$. It was proven that improved drug encapsulation, loading efficiency, prolonged drug release, stability upon storage, and simplified synthesis can be attained with NLCs [80].

Iqbal et al. developed silymarin-loaded NLC gel for the treatment of skin cancer. Silymarin NLC gel was evaluated for antiproliferative, antioxidant, anti-inflammatory, and antitumor activity. B16 melanoma cell line was used for ex vivo studies and albino mice were used as in vivo models to assess the above listed pharmacological activities. A significant reduction in the large volume tumors was observed. Levels of IL- $1 \alpha$ and TNF- $\alpha$ were lower along with greatly elevated levels of superoxide dismutase, catalase, and glutathione in the group treated with silymarin-NLC gel. Furthermore, basosquamous carcinoma was noticed in skin treated with placebo and squamous cell carcinoma was noticed in the skin treated with conventional gel. Silymarin-NLC gel was proven to be a better treatment regimen as compared to silymarinconventional gel [81].

Zhao et al. developed NLC loaded with Podophyllotoxin for skin targeting. Their study aimed to incorporate podophyllotoxin (POD) in NLCs and increase its skin distribution. Two NLC formulations were prepared with POD loading and were characterized. They were subjected to in vitro and in vivo experiments for comparison of their skin targeting efficiency. POD-NLC formulation 1 had a mean particle size of $106 \mathrm{~nm}$ whereas POD-NLC formulation 2 had a mean particle size of $219 \mathrm{~nm}$. Drug loading was relatively low for both formulations $-0.33 \%$, and $0.49 \%$, respectively. After topical application of both the NLC formulations, higher skin deposition was detected with formulation 1 during in vitro and in vivo studies. Distribution behavior of both the formulations was observed in vivo by replacing POD with Nile Red using confocal microscopy. Formulation 1 showed high fluorescent intensity which indicated that smaller size NLCs had better skin targeting efficiency. Obtained results were found in line with in vitro studies. Results of skin irritation studies on intact and diseased rabbit skin confirmed that its use is safe in topical application. It was concluded that while optimizing NLC formulation, mean particle size should be considered as an important parameter, considering its low loading capacity [82].

In one study by Rapalli et al., Curcumin-loaded NLCs were prepared to evaluate enhancement in the skin retention property. Results showed that the Curcumin-loaded NLCs had better skin retention and penetration capacity as compared to free Curcumin gel. Significant improvement in cellular uptake and skin deposition was observed
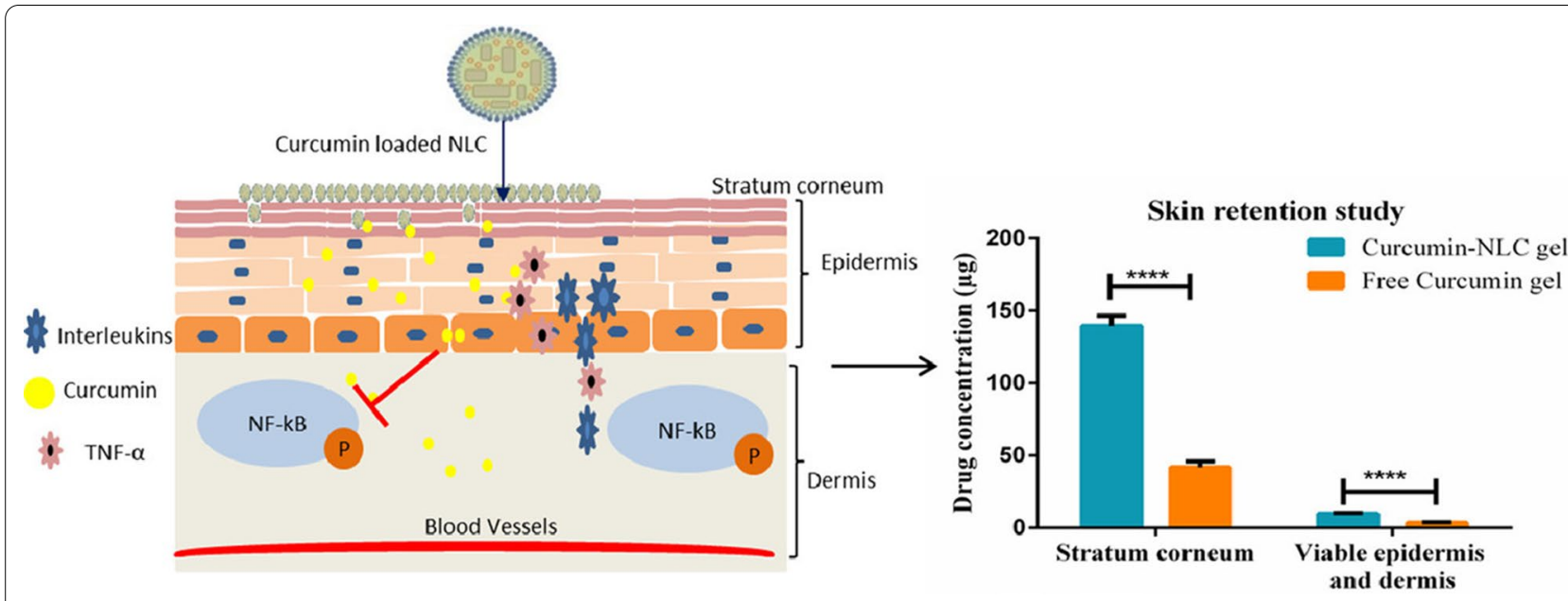

Fig. 3 Formulation of Curcumin based NLCs for skin cancer. Reproduced with permission from Rapalli et al. [80] 
with NLCs. Figure 3 is a schematic representation of the study [83].

Malta et al. encapsulated 1-carbaldehyde-3,4-dimethoxyxanthone (LEM2) into nanostructured lipid carriers using the ultrasonication method. The developed formulation had a high encapsulation efficiency and mean particle size suitable for topical application. LEM2 containing NLCs were found to be more cytotoxic against melanoma A375 cell line indicating improved efficacy of the developed formulation [84].

NLCs are the next-gen smart lipid nanoparticles that will be a choice of formulators for the delivery of lipophilic drugs. Ease of preparation and good encapsulation efficiency as well as the possibility of specific targeting will be the key factors driving their success.

\section{(ii) Dendritic nanoparticles}

Dendrimers are uniquely built nano-sized molecules with a central core and radially symmetric tree-like branches with well-defined, homogenous, unimolecular, and monodisperse structures. Dendrimers have characteristics to deliver nucleic acids, imaging agents, and both hydrophobic and hydrophilic drugs. They are multivalent as all the branches can have various terminal groups and the availability of several cavities $[85,86]$. Quite a lot of literature sources confirm the ability of dendrimers to induce specific targeting by ligands and destruction of tumors. They include oligopeptides, oligosaccharides, polyunsaturated fatty acids, folate, polysaccharides and tumor-associated antigens. However, a controlled release of drugs associated with dendrimers is still difficult to obtain. One approach is to incorporate a degradable link by synthesizing or conjugating the drug to dendrimers which can control the drug release [87]. Dendrimers were proven successful to be used for squamous cell carcinoma and melanoma by the means of therapy, immunotherapy, and radio-immunotherapy. They have also found applications in the diagnostic imaging of cancer cells, such as MRI. Gadolinium-conjugates dendrimers have allowed the selective comprehensive targeting and imaging of tumors [88].

Jiang $G$ et al. developed temozolomide-loaded dendritic nanoparticles for the treatment of melanoma. They evaluated the temozolomide (TMZ)loaded polyamide-amine dendrimer (PAMAM)-based nanodrug delivery system, and explored its ability to target human melanoma (A375) cells in vitro. The particles were synthesized using substitution/addition reaction and the complex was made using ultrasonic emulsification method. They then checked the targeting ability of prepared conjugates on A375 cells. The entrapment efficiency and drug loading of TMZ-PAMAM-PEG-GE11-HA was $\sim 50.63 \%$ and $\sim 10.4 \%$, respectively. TMZ-PAMAMPEG-GE11-HA targeted A375 cells in vitro. The TMZ-PAMAM-PEG-GE11-HA nanodrug delivery system was successfully prepared and demonstrated its potential for targeting A375 cells in vitro. This system enhanced the sensitivity of A375 cells to TMZ and provided a novel targeted strategy for the treatment of metastatic melanoma [89].

Dendrimer nanocomplexes are being explored for delivery of genetic materials by using iontophoresisassisted drug delivery. Peptide dendrimers are also under investigation for various therapeutic applications. Such advances in material science and drug delivery science will ensure better management of skin cancers in the future.

(b) Vesicular nanoformulations

(c) Liposomes

Liposomes are phospholipid vesicles (dimensions of 50-100 $\mathrm{nm}$ and even larger) that have a bilayered membrane structure, similar to that of biological membranes, together with an internal aqueous phase. Liposomes are classified according to size and number of layers into multi-, oligo-, or unilamellar. The aqueous core can be used for encapsulation of water-soluble drugs, whereas the lipid bilayers may retain hydrophobic or amphiphilic compounds. To escape from reticuloendothelial system (RES) uptake after i.v. injection, PEGylated liposomes, "stealth liposomes," were developed for reducing clearance and prolonging circulation half-life [90]. Liposomes show excellent circulation, penetration, and diffusion properties. The possibility to link the surface of the liposomes with ligands and/or polymers increases significantly the drug delivery specificity [91]. Early research demonstrated that liposomes remain in the tumor interstitial fluid just near the tumor vessels [92].

In one study, Wozniak et al. encapsulated Curcumin in liposomes and evaluated its photosensitizing efficacy following photodynamic therapy on Melanoma MUGMel2, Squamous Cell Carcinoma SCC-25, and Normal Keratinocyte $\mathrm{HaCaT}$ Cells. The liposomal Curcumin formulation exhibited improved bioavailability and increased stability revealing potent anti-cancer activity in squamous cell carcinoma and melanoma cell lines. On the other hand, decreased phototoxicity was found in normal skin keratinocytes $\mathrm{HaCaT}$ cells. Overall, the results suggested that the liposomal formulation of a poor soluble natural compound may improve photosensitizing properties of curcumin-mediated photo-dynamic therapy treatment in skin cancers and reduce toxicity in normal keratinocytes [93]. Currently, several liposomal 
formulations in the clinical practice contain several drugs for the treating of different types of cancer, including melanoma [94].

\section{(ii) Ethosomes}

Touitou et al. developed Ethosomes, deformable vesicles which have ethanol in their composition. Ethosomes are known for their high encapsulation capacity for polar as well as nonpolar drugs and can pass through the stratum corneum very easily. Ethosomes have a multilamellar structure and are made up of phospholipids, ethanol, and water which give them a higher encapsulation capacity. Ethosomes show a higher flexibility and fluidity than liposomes. Ethanol in the composition of ethosomes leads to the temporary disorganization of alcoholic lipid chains in the stratum corneum and promotes the penetration of soft carriers across the skin barrier [95].

Cristiano et al. studied the potential of sulforaphaneloaded ethosomes and transferosomes for the treatment of skin cancer. They prepared the formulations using phospholipon $90 \mathrm{G}$, sodium cholate hydrate, ethanol, and water. Developed products were evaluated for mean particle size, polydispersity index, deformability, drug encapsulation efficacy, and cutaneous penetration across human stratum corneum and epidermal layers. They found that ethosomes prepared using ethanol $40 \%(\mathrm{w} / \mathrm{v})$ and phospholipon 90G 2\% (w/v) have better stability and are more suitable as topical carriers for skin cancer [96].

Nayak et al. developed bioengineered ethosomes encapsulating silver nanoparticles and Tasar silk sericin proteins. The in vivo experiments exhibited the stimulation of IgM secretion with $\mathrm{T}$ cell-mediated immune response. This study proposes a novel, cost-effective, and alternative approach for targeted delivery of drugs for non-melanoma skin carcinoma [97].

The ability of these nanostructures to perturb the lipid barrier will make them an attractive choice for the delivery of drugs that are difficult to deliver through the percutaneous route. Bioengineered ethosomes are currently under investigation.

\section{(iii) Transferosomes}

Cevc et al. described the Transfersomes ${ }^{\circledR}$, so-called ultra-deformable liposomes for the first time [98]. As with ethosomes ${ }^{\circledR}$, the flexibility of transferosomes ${ }^{\circledR}$ is attributed to their specific composition. Phospholipids and sodium cholate are the main components, which reduces interfacial tension by acting as an edge activator, hence increasing the deformability of the vesicle bilayers. Thanks to their exceptional flexibility, transferosomes are said to transgress as intact vesicles through the dermal layers to the systemic circulation. To repurpose carvedilol for skin cancer prevention, a novel topical transferosomes based formulation was developed by Chen et al.. The optimized formulation was composed of carvedilol, soy phosphatidylcholine, and Tween-80 at a ratio of 1:3:0.5 and exhibited a particle size of $115.6 \pm 8.7 \mathrm{~nm}$, a zeta potential of $11.34 \pm 0.67 \mathrm{mV}$, and encapsulation efficiency of $93.7 \pm 5.1 \%$. The developed delivery system of carvedilol was proven efficacious in preventing ultravioletinduced skin damage and carcinogenesis [99].

(iii) Colloidal nanoformulations

(iv) Nanoemulsions

Nanoemulsions can be used as a vehicle for the BCS class II and IV drugs as they are colloidal dispersions and constituted of safe grade excipients [100, 101]. Nanoemulsion is a dispersion of two heterogeneous liquids, one in droplet form and another as the continuous phase, which leads to better stability and solubility. The drug is protected from degradation and plasma half-life is increased by the encapsulation mechanism.

Nanoemulsions have characteristics like large surface area, zeta potential, elevated circulation half-life, and tissue targeting. These essential qualities provoke the interest of scientist to explore the use of nanoemulsion in cancer therapy. Due to its small size, nanoemulsion can easily accumulate and pass through barriers of vascularized tissues in the surrounding of the cancer cells. Above all this, they can also be functionalized according to the types of drugs to be encapsulated and specific targets [102, 103].

Shakeel et al. [104] investigated the use of 5-fluorouracil (5-FU) in nanoemulsion systems. 5-FU shows extreme bioavailability and severe adverse effects; hence, its oral delivery is very difficult. They developed and evaluated low HLB surfactant nanoemulsion of 5-FU for topical chemoprevention of skin cancer. The oil phase titration method was used to prepare low HLB surfactant nanoemulsion. Thermodynamically stable nanoemulsions were evaluated for droplet size analysis, zeta potential, viscosity, and refractive index. In vitro skin permeation studies of the optimized formulation were performed by mounting rat skin on Franz diffusion cell. Stability studies and in vitro cytotoxic studies were also performed on a melanoma cell line for the optimized formulation. 22.33 folds enhancement was found with the optimized formulation when compared with control and other formulations. Optimized nanoemulsion of 5-FU showed better efficacy than free 5-FU during in vitro cytotoxicity studies on SKMEL-5 cancer cells.

Tagne et al. developed nanoemulsion of DAC for the treatment of melanoma and they found that nanoemulsion delivery systems for drugs may provide more efficacious treatment of certain cancers and with fewer adverse effects. The results proved that DAC can also be 
administered as IM and/or topical application other than conventional IV injection. They also showed that when nanoemulsion is delivered to the nude mice, it penetrates better through the cell membrane. It was concluded that nanoemulsions allow superior skin penetration after photoactivation of DAC and hence, it is released intracellularly which ultimately makes it suitable for topical application [105].

Adhikari et al. investigated the synergistic effect of cold atmospheric plasma (CAP) and Silymarin Nanoemulsion (SN) for inhibition of melanoma. They used a flow cytometer to examine the combined treatment of CAP and SN on G-361 human melanoma cells by considering various cellular markers as key evaluation parameters. Using western blotting and microscopy assessment, the effect of dual treatment on the epithelial-mesenchymal transition (EMT) was checked considering (HGF/cMET) pathway, sphere formation, and the reversal of EMT. Cellular toxicity was increased in a time-dependent manner when co-treatment of SN and CAP was given and showed maximum toxicity at $200 \mathrm{nM}$ in $24 \mathrm{~h}$. ROS and RNS generation was found less than 3 times and less than 2.5 times, respectively, in the dual treated samples when compared with the control. They also assessed DNA, increase in Caspase 8,9,3/7, PARP level and apoptotic genes level. EMT markers, melanoma cells (BRAF, NAMPT) and stem cells (CD133, ABCB5) markers were decreased. In vivo results confirmed the reduction in tumor size, weight, and SN with PAM [106].

Anuchapreeda et al. prepared Curcumin-loaded nanoemulsion for the treatment of cancer. The study showed the successful fabrication of small-sized nanoemulsion loaded with Curcumin. For the preparation of Curcumin lipid nanoemulsion, a thin layer hydration method was used. Instead of HCO-60, Tween 80 was used as a surfactant to achieve small particle size. Prepared nanoemulsion had a particle size of $47-56 \mathrm{~nm}$ with a small polydispersity index. The addition of Curcumin was continued until Curcumin incorporated in the emulsion reached saturation level. The composition of optimized Curcumin lipid nanoemulsions was $1 \mathrm{~mL}$ soybean oil, 30 mg Curcumin, 250 mg HEPC, 375 mg Tween 80,

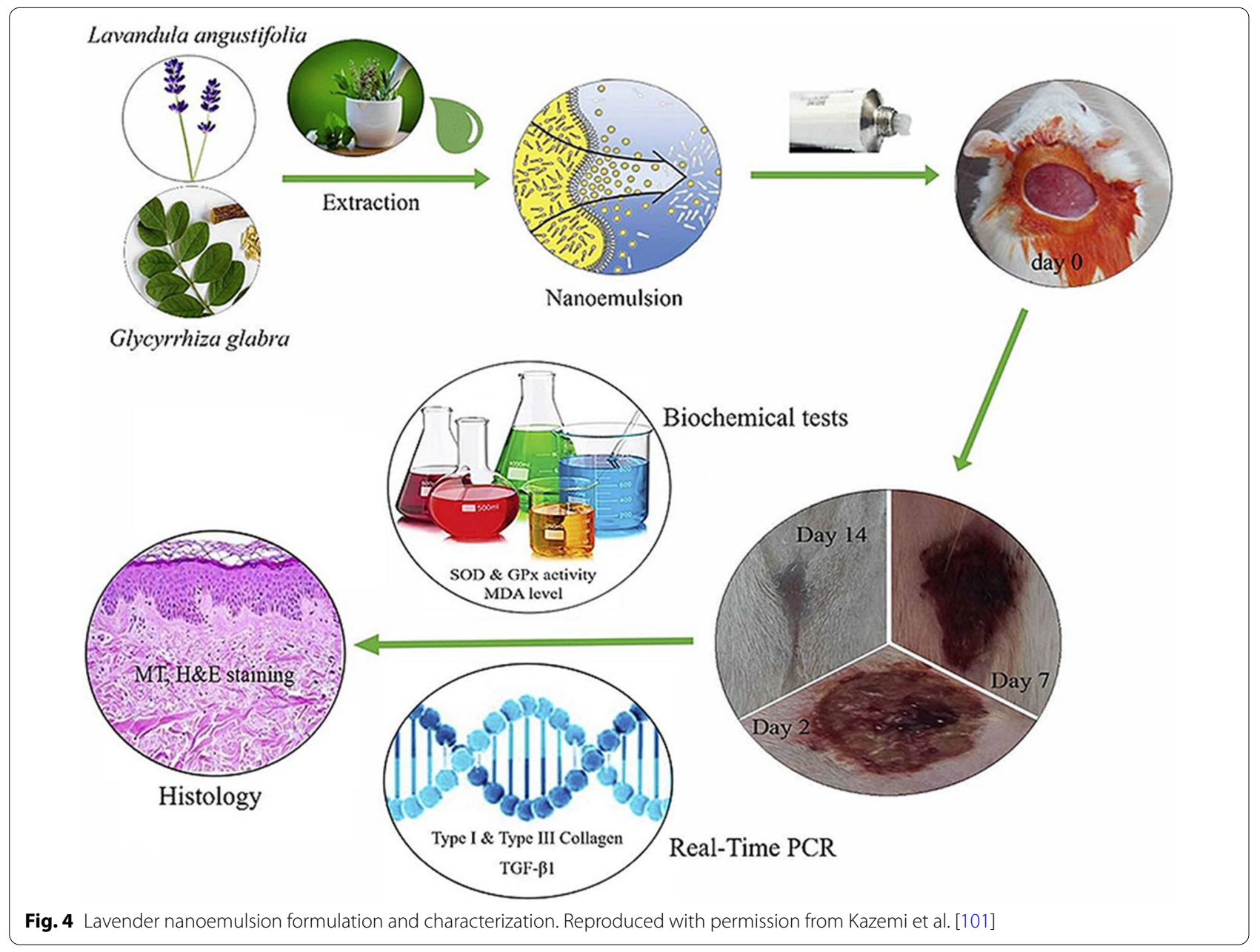


and $30 \mathrm{~mL}$ water. The stability of the prepared nanoemulsion was found to be of 60 days at $4{ }^{\circ} \mathrm{C}$. The results from the cytotoxicity test assured the use Curcumin-loaded nanoemulsion as an effective nanodelivery vehicle [107].

Kazemi et al. developed a nanoemulsion of lavender oil and licorice extract to check its potential in deep skin wound healing by evaluation of biochemical parameters, gene expression, and histopathological examination. These agents improve collagen deposition and accelerate re-epithelialization. Prepared nanoemulsion has antioxidant properties, which is very essential in anti-cancer activity as well. Figure 4 depicts the formulation and evaluation of nanoemulsion of lavender essential oil and licorice extract and their promising results to be used for dermal delivery [108].

Daniela et al. developed nanoemulsions for topical delivery of a cytotoxic agent piplartine. The nanoemulsions were modified with the bioadhesive polysaccharides namely chitosan and sodium alginate. Due to the encapsulation, there was a 2.8 -fold reduction in the drug IC50 against melanoma cells. The developed formulation exhibited marked epidermis destruction in a 3D melanoma model, demonstrating efficacy [109]. The role of nanoemulsions is being explored as Nanoemulgels, development of nanoemulsions for polychemotherapy, as vaccine carriers and as theranostic agents.

\section{(ii) Nanofibres}

Yang et al. have developed an implantable device containing nanofibre loaded with micelle for effective and safe cancer therapy. First, Doxorubicin was encapsulated in the folate conjugated poly( $\varepsilon$-caprolactone)-poly(ethylene glycol) copolymer by self-assembling into active targeting micelles. Folate receptors are over-expressed on the surface of solid tumors to which folate ligands can bind readily. Then, coaxial electrospinning was used to form core-shell polymeric nanofibres in which micelles can be trapped in the core region. The inner phase of fibers was made up of an aqueous solution of PVA and micelles and gelatin solution makes the outer phase. Electrospun fibers have high drug loading capacity due to the big surface area to volume ratio. They are excellent drug carriers and hence can be implanted. The developed nanofiber has a degradable matrix which releases active-targeting micelles slowly and they get accumulated quickly in the vicinity of the tumor tissue via the EPR effect. Later these micelles are internalized into tumor cells by folate receptors mediated endocytosis. Implantable nanofiber device is capable of maintaining low systemic drug exposure to normal tissues as it can ensure therapeutic drug levels at the tumor site for a longer period though they are loaded with a low dosage of the drug. Moreover, it could be concluded that with this kind of implantable device system dosing frequency can be reduced which in turn can potentially improve the quality of life and enhance compliance of the patient [110].

Another study was carried out by Rengifo et al. where nanofibers mats were prepared using PEO-chitosan and were loaded with carboxymethyl-hexanoyl chitosan/ dodecyl sulfate nanoparticles loaded with pyrazoline. Nanofiber mats and nanoparticles formed double barrier nanomaterial which showed sustained and continuous release of the active material. Reduced IC50 was achieved with nanoparticle-loaded nanofiber for the treatment of skin cancer. The combination approach was proven beneficial in terms of enhanced effectiveness of the active

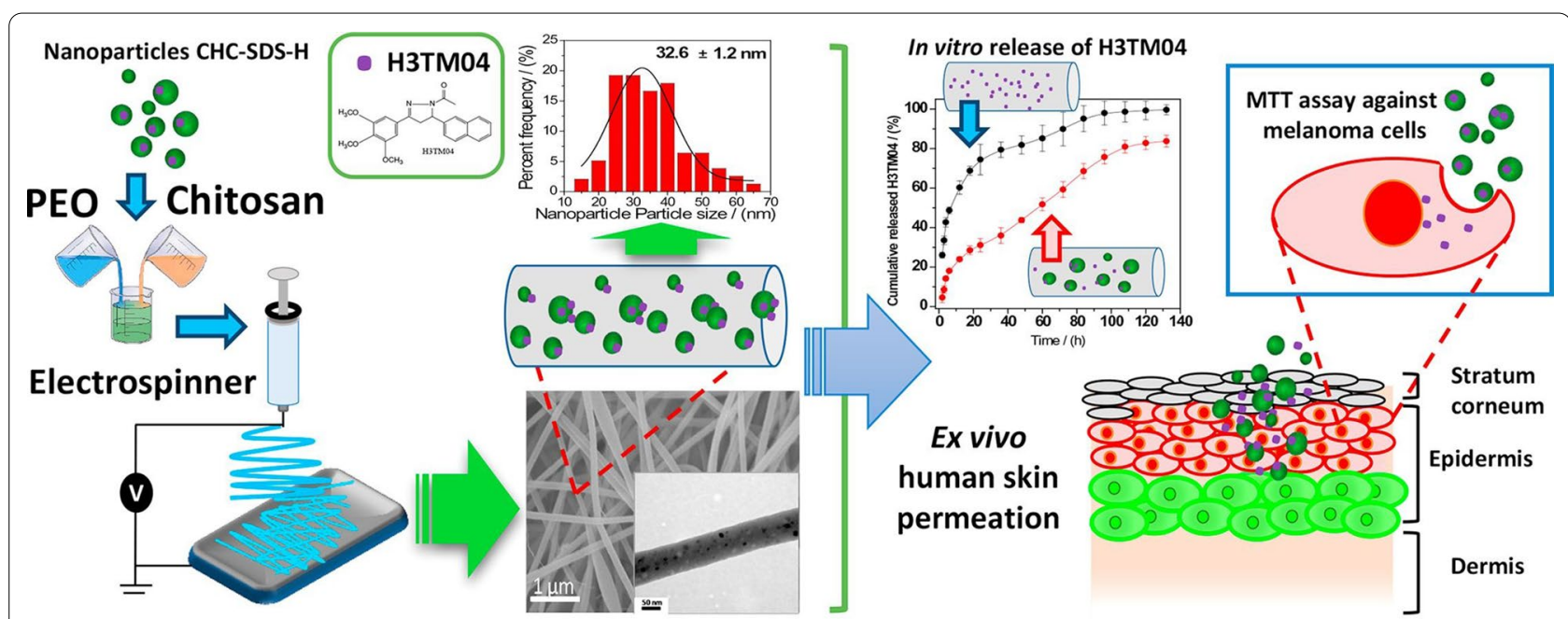

Fig. 5 PEO-Chitosan Nanofibers employed for the management of skin cancer. Reproduced with permission from Rengifo et al. [103] 
compound for the treatment of skin cancer [111]. Figure 5 is a graphical representation of the above-mentioned study.

Balashanmugam et al. developed nanofibers-based scaffolds using biocompatible and non-toxic synthetic polymers [PVA, PCL] with phytosynthesized AuNPs and curcumin for the treatment of skin cancer. The results from their study have confirmed the anticancer activity of the developed formulation on skin cancer cell lines [A375 skin cancer cell line]. The treatment with nanofibers in cancer cells exhibited more cytotoxicity than in the normal cells [s 3 T3 fibroblast] where similar concentrations were used thereby proving selective toxicity [112].

\section{Overcoming challenges with nanoformulations}

Many industries and governments are investing huge amounts and in-depth research is being undertaken on nanotechnology for cancer treatment since the last decade. However, nanoformulations face the problem of getting translated into clinical practice. There are many scientific publications regarding the development of the nanoformulation for the treatment of cancer, but they are barely at the stage of in vivo clinical evaluation. Very few nanoformulations can successfully reach the clinical trial phase. Integrating expert input from various fields is also a challenging task. There is a requirement of clear regulatory guidelines, focused efforts of relevant discipline, and identification of gaps in current knowledge to translate nanotechnology-based therapies into clinically marketable products. Nanoformulations face challenges like bioadhesiveness, permeation into tumor tissue, controlled release of the drug, and toxicity for which scientists have given few solutions. However, they are to be explored in detail, taking regulatory requirements into the consideration. Table 3 shows some strategies explored by scientists for targeting skin cancer.

\section{New biological approaches}

While nanoparticulate systems developed using lipids, polymers and surfactants have progressed tremendously, topical delivery of therapeutic peptides, proteins, and nucleic acids using such delivery vehicles has also advanced along with the application of small molecule drugs. Apart from that, newer biological approaches utilizing biologicals (proteins and peptides including antibodies and nucleic acids as drug carriers have also evolved. Such few systems are Framework nucleic acid (FNA) and protein-drug conjugates or peptide drug conjugates.

One new nucleic acid based nanoparticulate delivery system which has shown great potential for topical delivery is spherical nucleic acids (SNAs). SNAs are core-shell type nanostructures made of gold nanoparticulate core densely covered with nucleic acid molecules which can be siRNA, mRNA, or oligonucleotide. Studies have established their topical delivery potential for therapeutic/ diagnostic use in which SNAs can cross stratum corneum and epidermal layers and reach the dermis [113-115]. Zheng et al. [116] carried out proof-of-concept studies with SNAs for delivery of EGFR siRNA for topical gene regulation which otherwise would require skin barrier breaching or transfection agents such as liposomes or viruses. They showed SNAs showed higher potency ( $>100$ times more) and sustained gene suppression compared to lipid agents in vitro. They were able to permeate through mouse skin and human epidermis within hours of topical application, however, in vivo in mice they did not show any systemic absorption and were not detected in internal organs. They concluded that such SNAs may be promising for topical gene delivery for cutaneous tumors and other inflammatory conditions. Another study by Nemati et al. evaluated SNAs of EGF and EGFR siRNAs $(\sim 12 \mathrm{~nm}$ size with $-28 \mathrm{mV}$ zeta potential) for topical delivery for psoriasis treatment [117]. Thorough in vitro and in vivo evaluation of safety and efficacy was carried out. SNAs were able to inhibit cell proliferation in an imiquimod-based mouse model of psoriasis. A recent study by Yeo et al. showed SNAs made of an oligonucleotide with a small fluorophore-tagged reporter sequence attached to a larger recognition sequence [115]. These SNAs (termed NanoFlares) are used to detect abnormal scar tissue after topical application, which is accomplished by quenching of reporter sequence signal by the presence of target mRNA sequence in skin tissue. In all the above studies, researchers were able to incorporate SNAs in commercially available petrolatum-based moisturizer Aquaphor ${ }^{\circledR}$ without any issues for topical application. While there are no reports of topically delivered SNAs for the treatment of skin cancers, the above proofof-concept studies strongly warrant their therapeutic potential in skin cancer.

Progress made in the field of SNAs also triggered similar concepts of utilizing nucleic acids for topical delivery of drugs as well in which nucleic acid can act as a carrier for other drugs. An apt example is FNAs which represent a 3D network of single-stranded deoxyribonucleic acid molecules to generate nanoparticulate structural features which can be utilized for drug delivery $[118,119]$. These structures differ in their DNA spatial arrangements giving different sizes and shapes. Recently, such DNA origami structures have been successfully employed as topical diagnostic tools to detect abnormal scar detection. A recent study by Wiraja et al. evaluated the topical application of various FNAs of different particle sizes (from 20 to $200 \mathrm{~nm}$ ) and different configurations (tetrahedral, nanotubes etc.) on penetration in mice, pigs, and 
Lalan et al. Futur J Pharm Sci ～(2021) 7:179

Page 18 of 25

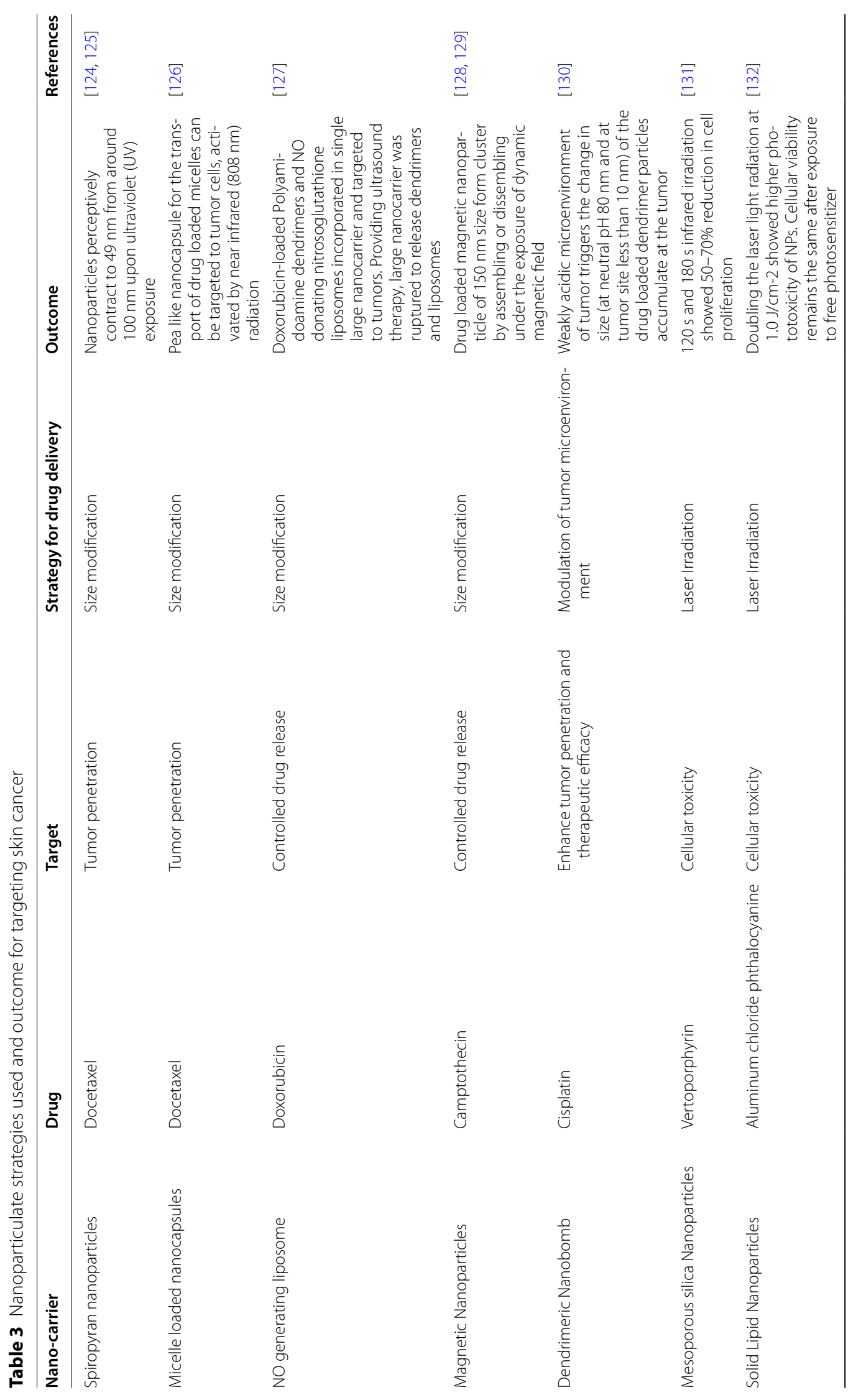


Lalan et al. Futur J Pharm Sci ～(2021) 7:179

Page 19 of 25

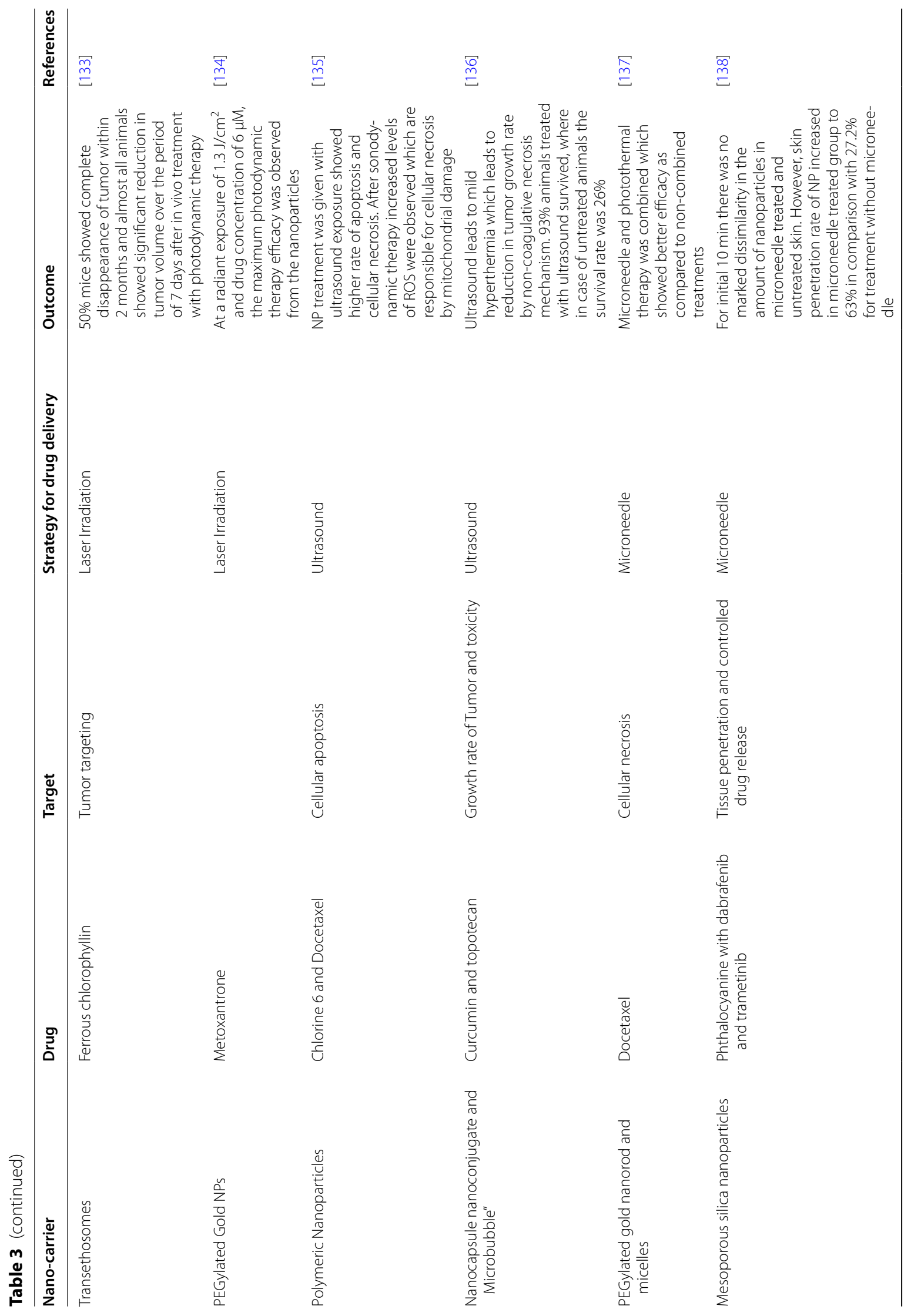




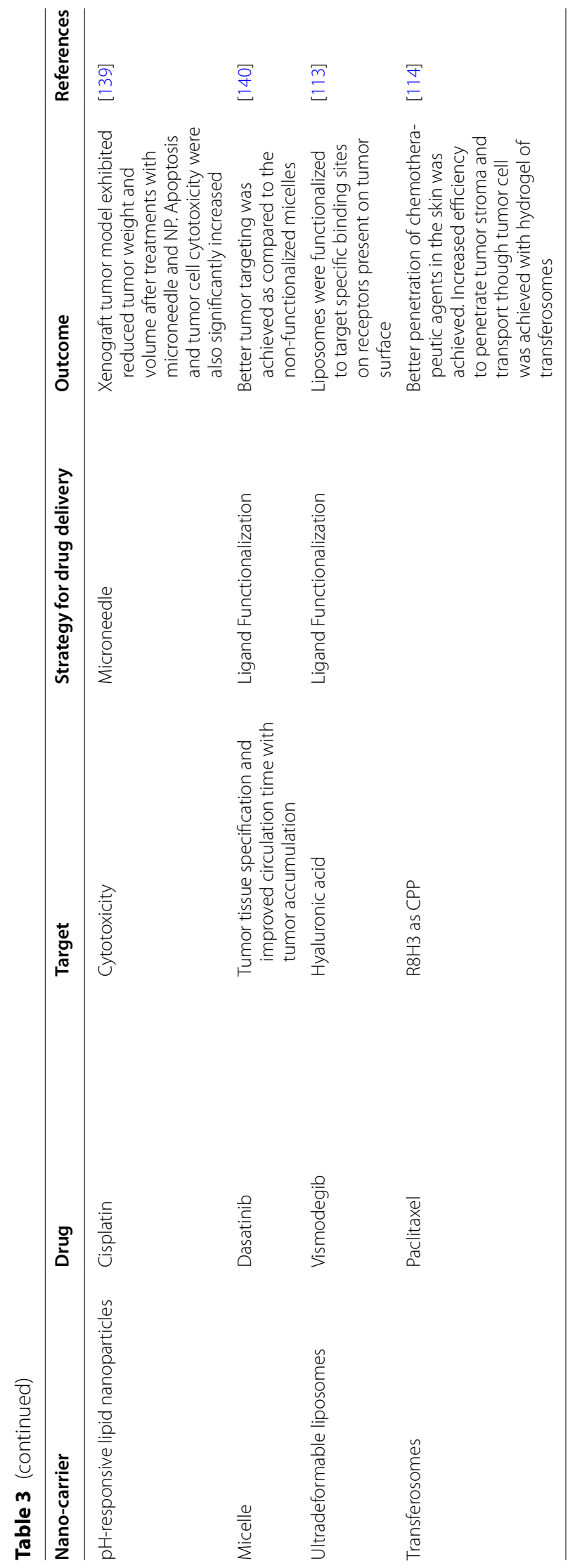


humans [120]. There was a size- and shape-dependence of skin penetration among different FNAs with $20 \mathrm{~nm}$ tetrahedral FNAs showing penetration depth of up to $350 \mu$ while retaining their integrity as indicated by FRET-incorporated FNAs. A comparison was also made between the doxorubicin loaded FNAs (TH21-tetrahedral FNAs with $\sim 20 \mathrm{~nm}$ size) with other nanoparticulate systems such as liposomes, PLGA nanoparticles, and with free drug applied on intact skin and microneedle bored skin. Results demonstrated that despite lower drug loading compared to PLGA nanoparticles and liposomes, they were able to carry more drug across skin providing more penetration depth and also improving tumor burden in a melanoma tumor model in mice. In vivo, topical application of doxorubicin using FNAs for treatment of melanoma tumors showed enhanced performance (2 times inhibition compared to other nanocarriers such as polymeric nanoparticles or liposomes). Also, the FNAs themselves did not cause safety concerns as shown by minimal effects to the skin morphology. Same group claimed that use these FNAs for doxorubicin delivery through skin for melanoma treatment opens up a new era in drug delivery systems for nucleic acids being used as drug delivery carrier rather than being just therapeutic molecules [121].

Another field that has seen rapid growth is the use of cell-penetrating peptides (CPPs) which offer safer options for drug delivery across skin (so-called SPPs i.e. skin penetrating peptides). Usually, these peptides bear common features of having an arginine-rich structure and cationic nature. Kumar et al. compared different SPPs (SPACE peptide, TD-1, polyarginine, a dermislocalizing peptide, and skin penetrating linear peptide) for delivery of a model drug (cyclosporin A) to understand their mechanism. The study suggested that among these, SPACE, TD-1, and polyarginine enhanced drug penetration better than the other two. They did so, not by disrupting the lipid barrier of the skin, but by altering the skin proteins' secondary structures and enhancing transcellular absorption of cyclosporin A. More interestingly, their interaction with keratin is better correlated with drug transport. Other studies by Chen et al. have established the potential of CPPs as carriers for topical application for siRNA and cyclosporine A [122]. A more recent study demonstrated a specific CPP (IMTP8- Institute of Microbial Technology-Peptide 8 with peptide sequence of RRWRRWNRFNRRRCR) is able to carry different cargos more effectively across skin than TAT peptide (GRKKRRQRRRPPQ) [123]. Also, in vivo studies in mouse showed that IMT-P8 was able to deliver a range of cargos (FITC-a small molecule, KLA-a proapoptotic peptide, and GFP-green fluorescent protein).
These studies provide a groundwork that similar strategies can be used for melanoma treatment using suitable drug molecules.

\section{Conclusions}

Nanotechnology is beneficial in achieving the desired rate of release and skin targeting by modifying permeation and penetration of active substances. Improved retention in the skin ensures drug localization in the stratum corneum and protection of drugs against chemical or physical changes. Nano-formulations can empower the clinician to safely and effectively target multiple therapeutics to the resistant oncogenic tissues; where they can display synergy, complement therapeutics with diagnostics to achieve better therapeutic outcomes. Enormous research is being directed towards the development of carrier based therapeutics for immunologicals and nucleic acids for effective treatment of melanoma/ skin cancer. The research output is too promising in treating melanoma effectively. However, there are a few challenges like the toxicity of the nanoformulation, dose determination, cost-effectiveness, etc. are remaining to be resolved and a challenge for its bedside translation. The economics can tilt in the favour of nanoformulations because of their innumerable benefits. For oral and parenteral routes, nanoformulations have entered the market with regulatory approval and it is expected that topical nanoformulations too will be commercialized successfully in near future. Thus, the development of nanoformulations holds lots of promises for future skin cancer therapy.

\section{Abbreviations \\ COX-2: Cyclo-oxygenase-2; ROS: Reactive oxygen species; PAH: Polycyclic aromatic hydrocarbons; HPV: Human papilloma virus; SCC: Squamous cell carcinoma; PDT: Photodynamic therapy; NFs: Nanoformulations; SLNs: Solid lipid nanoparticles; Dox: Doxorubicin; NLCs: Nanostructured lipid carriers; DAC: Dacarbazine; POD: Podophyllotoxin; TMZ: Temozolomide; PAMAM: Polyamide- amine dendrimer; RES: Reticuloendothelial system; 5-FU: 5-Fluorouracil; CAP: Cold atmospheric plasma; SN: Silymarin nanoemulsion; EMT: Epithelial-mes- enchymal transition; SNAs: Spherical nucleic acids.}

\section{Acknowledgements \\ None.}

Authors' contributions

PS and KB contributed to conception and design of the article; KP and PP contributed to collection of literature and drafting the article; TM contributed to analysis and interpretation of the relevant literature, final approval of the version to be published; ML contributed to critical revision of the article. All authors read and approved the final manuscript.

Funding

None.

Availability of data and materials

Not applicable. 


\section{Declarations}

Ethics approval and consent to participate

Not applicable.

\section{Consent for publication}

Not applicable.

\section{Competing interests}

The authors declare that they have no competing interests.

\section{Author details}

${ }^{1}$ Babaria Institute of Pharmacy, BITS Edu Campus, NH\#8, Varnama, Vadodara, Gujarat 391240, India. ${ }^{2}$ Department of Pharmaceutics, Maliba Pharmacy College, Uka Tarsadia University, Gopal Vidyanagar, Tarsadi, Bardoli, Dist: Surat, Gujarat, India. ${ }^{3}$ Shobhaben Pratapbhai Patel School of Pharmacy and Technology Management, SVKMs NMIMS, V.L. Mehta Road, Vile Parle (W), Mumbai, Maharashtra 400056, India. ${ }^{4}$ Institute of Pharmacy, Nirma University, Sarkhej Gandhinagar Highway, Ahmedabad, Gujarat 382482, India. ${ }^{5}$ Department of Pharmaceutical Sciences, Saurashtra University, Rajkot, Gujarat 360005, India.

Received: 15 July 2021 Accepted: 21 August 2021

Published online: 30 August 2021

\section{References}

1. Benson HAE, Grice JE, Mohammed Y et al (2019) Topical and transdermal drug delivery: from simple potions to smart technologies. Curr Drug Deliv 16(5):444-460

2. Kumar S, Zakrewsky M, Chen M et al (2015) Peptides as skin penetration enhancers: mechanisms of action. J Control Release 199:168-178

3. WHO (2020) Skin cancers. https://www.who.int/uv/faq/skincancer/en/ index $1 . \mathrm{htm}$

4. CDC (2020) Melanoma of the skin statistics. https://www.cdc.gov/ cancer/skin/statistics/index.htm

5. Apalla Z, Nashan D, Weller RB et al (2017) Skin cancer: epidemiology, disease burden, pathophysiology, diagnosis, and therapeutic approaches. Dermatol Ther (Heidelb) 7(Suppl 1):5-19

6. https://gco.iarc.fr/today/online-analysis-table

7. Rubin Al, Chen EH, Ratner D (2005) Basal-cell carcinoma. N Engl J Med 353(21):2262-2269

8. Leiter U, Garbe C (2008) Epidemiology of melanoma and nonmelanoma skin cancer - the role of sunlight. Adv Exp Med 624:89-103

9. D'Orazio J, Jarrett S, Amaro-Ortiz A et al (2013) UV radiation and the skin. Int J Mol Sci 14(6):12222-12248

10. Tanese K, Nakamura Y, Hirai I et al (2019) Updates on the systemic treatment of advanced non-melanoma skin cancer. Front Med (Lausanne) $16: 160$

11. Bommareddy PK, Patel A, Hossain S et al (2017) Talimogene Laherparepvec (T-VEC) and other oncolytic viruses for the treatment of melanoma. Am J Clin Dermatol 18(1):1-15

12. Nan W, Ding L, Chen $H$ et al (2018) Topical use of quercetin-loaded chitosan nanoparticles against ultraviolet B radiation. Front Pharmacol 9:826

13. Tong L, Wu S (2018) The mechanisms of carnosol in chemoprevention of ultraviolet B-light-induced non-melanoma skin cancer formation. Sci Rep 8(1):3574

14. Aziz MH, Reagan-Shaw S, Wu J et al (2005) Chemoprevention of skin cancer by grape constituent resveratrol: relevance to human disease. FASEB J 19(9):1193-1195

15. Abo Aasy NK, Ragab D, Sallam MA et al (2019) A comparative study: the prospective influence of nanovectors in leveraging the chemopreventive potential of COX-2 inhibitors against skin cancer. Int J Nanomedicine 14:7561-7581

16. Smijs TG, Pavel S (2011) Titanium dioxide and zinc oxide nanoparticles in sunscreens: focus on their safety and effectiveness. Nanotechnol Sc Appl 13(4):95-112
17. Van Smeden J, Bouwstra JA (2016) Stratum corneum lipids: their role for the skin barrier function in healthy subjects and atopic dermatitis patients. Curr Probl Dermatol 49:8-26

18. Elias PM (2008) Skin barrier function. Curr Allergy Asthma Rep 8(4):299-305

19. Gordon R (2013) Skin cancer: an overview of epidemiology and risk factors. Semin Oncol Nurs 29(3):160-169

20. Jepps OG, Dancik Y, Anissimov YG, Roberts MS (2013) Modeling the human skin barrier - towards a better understanding of dermal absorption. Adv Drug Deliv Rev 65(2):152-168

21. Goyal N, Thatai P, Sapra B (2017) Skin cancer: symptoms, mechanistic pathways and treatment rationale for therapeutic delivery. Ther Deliv 8(5):265-287

22. Kumar $V$, Abbas AK, Fausto N, Mitchell R (2007) The skin. Robbins basic pathology, 8th edn. Saunders Elsevier, Philadelphia

23. Rastrelli M, Tropea S, Rossi CR, Alaibac M (2014) Melanoma: epidemiology, risk factors, pathogenesis, diagnosis and classification. vivo 28(6):1005-1011

24. Awad F, Assrawi E, Louvrier C et al (2018) Photoaging and skin cancer: Is the inflammasome the missing link? Mech Ageing Dev 172:131-137

25. Chen AC, Halliday GM, Damian DL (2013) Non-melanoma skin cancer: carcinogenesis and chemoprevention. Pathology 45(3):331-341

26. Singh M, Suman S, Shukla Y (2014) New enlightenment of skin cance chemoprevention through phytochemicals: in vitro and in vivo studies and the underlying mechanisms. Biomed Res Int 2014:1-18

27. Marshall SE, Bordea C, Haldar NA et al (2000) Glutathione S transferase polymorphisms and skin cancer after renal transplantation. Kidney Int 58:2186-2193

28. Nan H, Kraft P, Hunter DJ, Han J (2009) Genetic variants in pigmentation genes, pigmentary phenotypes, and risk of skin cancer in Caucasians. Int J Cancer 125(4):909-917

29. Ainger SA, Jagirdar K, Lee KJ, Soyer HP, Sturm RA (2017) Skin pigmentation genetics for the clinic. Dermatol 233(1):1-5

30. Malkinson FD, Rothman S (1957) Skin cancer: its causes, prevention, and treatment. CA Cancer J Clin 7(6):190-195

31. Bichakjian C, Armstrong A, Baum C et al (2018) Guidelines of care for the management of basal cell carcinoma. J Am Acad Dermatol 78(3):540-559

32. Swetter SM, Tsao H, Bichakjian CK et al (2019) Guidelines of care for the management of primary cutaneous melanoma. J Am Acad Dermatol 80(1):208-250

33. Alam M, Armstrong A, Baum C et al (2018) Guidelines of care for the management of cutaneous squamous cell carcinoma. J Am Acad Dermatol 78(3):560-578

34. Gracia-Cazana T, Salazar N, Zamarron A et al (2016) Resistance of nonmelanoma skin cancer to nonsurgical treatments. Part II: pho todynamic therapy, Vismodegib, Cetuximab, Intralesional Methotrexate, and Radiotherapy. Actas Dermo-Sifiliográficas (Engl Ed) 107(9):740-750

35. Tracey EH, Vij A (2019) Updates in melanoma. Dermatol Clin 37(1):73-82

36. Dubas LE, Ingraffea A (2013) Nonmelanoma skin cancer. Facial Plast Surg Clin N Am 21(1):43-53

37. Gracia-Cazana T, Gonzalez S, Gilaberte Y (2016) Resistance of nonmelanoma skin cancer to nonsurgical treatments. Part I: topical treatments. Actas Dermo-Sifiliográficas (Engl Ed) 107(9):730-739

38. Granados K, Hüser L, Federico A et al (2020) T-type calcium channel inhibition restores sensitivity to MAPK inhibitors in de-differentiated and adaptive melanoma cells. Br J Cancer 17:1-4

39. https://www.accessdata.fda.gov/drugsatfda_docs/label/2010/02072 3s022 lbl.pdf. Cited 2020 Sep 10

40. Levy S, Furst K, Chern W (2001) A pharmacokinetic evaluation of $0.5 \%$ and $5 \%$ fluorouracil topical cream in patients with actinic keratosis. Clin Ther 23(6):908-920

41. https://www.accessdata.fda.gov/drugsatfda_docs/label/2012/20338 8lbl.pdf. Cited 2020 Sep 10

42. Yue Q, Chen YH, Mulder T et al (2011) Absorption, distribution, metabolism, and excretion of [14C] GDC-0449 (vismodegib), an orally active hedgehog pathway inhibitor, in rats and dogs: a unique metabolic pathway via pyridine ring opening. Drug Metab Dispos 39(6):952-965 
43. https://www.accessdata.fda.gov/drugsatfda_docs/label/2012/20283 3lbl.pdf. Cited 2020 Sep 10

44. https://www.accessdata.fda.gov/drugsatfda_docs/label/2000/21005lbl pdf. Cited 2020 Sep 10

45. https://www.accessdata.fda.gov/drugsatfda_docs/label/2012/12508 4s0228lbl.pdf. Cited 2020 Sep 10

46. Lee CM, Tannock IF (2010) The distribution of the therapeutic monoclonal antibodies cetuximab and trastuzumab within solid tumors. BMC Cancer 10(1):255

47. Loo TL, Housholder GE, Gerulath AH et al (1976) Mechanism of action and pharmacology studies with DTIC (NSC-45388). Cancer Treat Rep 60:149-152

48. Nathanson L, Wolter J, Horton J et al (1971) Characteristics of prognosis and response to an imidazole carboxamide in malignant melanoma. Clin Pharmacol Ther 12:955-962

49. Costanza ME, Nathanson L, Lenhard R et al (1972) Therapy of malignant melanoma with an imidazole carboxamide and bischloroethyl nitrosourea. Cancer 30:1457-1461

50. Luce JK, Thurman WG, Isaacs BL et al (1970) Clinical trials with the antitumor agent 5-(3,3-dimethyl-1-triazeno) imidazole-4-carboxamide (NSC-45388). Cancer Treat Rep 54(2):119-124

51. https://www.accessdata.fda.gov/drugsatfda_docs/label/2018/21049 6lbl.pdf. Cited 2020 Sep 10

52. Center for drug evaluation and research, Pharmacology Review. https:// www.accessdata.fda.gov/drugsatfda_docs/nda/2018/210496Orig1s000 MultidisciplineR.pdf. Cited 2020 Sep 10

53. https://www.accessdata.fda.gov/drugsatfda_docs/label/2017/20242 9s012lbl.pdf. Cited 2020 Sep 10

54. https://www.accessdata.fda.gov/drugsatfda_docs/label/2014/20280 6s002lbl.pdf. Cited 2020 Sep 10

55. Center for drug evaluation and research, Pharmacology Review. https:// www.accessdata.fda.gov/drugsatfda_docs/nda/2013/202806Orig1s000 PharmR.pdf. Cited 2020 Sep 10

56. https://www.accessdata.fda.gov/drugsatfda_docs/label/2018/12537 7s094lbl.pdf. Cited 2020 Sep 10

57. Patel SP, Woodman SE (2011) Profile of ipilimumab and its role in the treatment of metastatic melanoma. Drug Des Dev Ther 5:489-495

58. https://www.accessdata.fda.gov/drugsatfda_docs/label/2019/12555 4s070lbl.pdf. Cited 2020 Sep 10

59. Centanni M, Moes DJ, Trocóniz IF et al (2019) Clinical pharmacokinetics and pharmacodynamics of immune checkpoint inhibitors. Clin Pharmacokinet 28:1-23

60. https://www.accessdata.fda.gov/drugsatfda_docs/label/2019/12551 4s040lbl.pdf. Cited 2020 Sep 10

61. England CG, Ehlerding EB, Hernandez R et al (2017) Preclinical pharmacokinetics and biodistribution studies of $89 \mathrm{Zr}$ - labeled pembrolizumab. J Nucl Med 58(1):162-168

62. https://www.accessdata.fda.gov/drugsatfda_docs/label/2015/20619 2s000lbl.pdf. Cited 2020 Sep 10

63. Center for drug evaluation and research, Pharmacology Review. https:// www.accessdata.fda.gov/drugsatfda_docs/nda/2015/206192Orig1s000 PharmR.pdf. Cited 2020 Sep 15

64. https://www.accessdata.fda.gov/drugsatfda_docs/label/2018/21049 8lbl.pdf. Cited 2020 Aug 30

65. European Medicine agency, Science medicine Health. https://www. ema.europa.eu/en/documents/assessment-report/mektovi-epar-public-assessment-report_en.pdf. Cited 2020 Sep 10

66. www.fda.gov, Framework for FDA's Real-World Evidence Program. https://www.fda.gov/media/120060/download. Cited 2020 Sep 10

67. Krishnan V, Mitragotri S (2020) Nanoparticles for topical drug delivery: potential for skin cancer treatment. Adv Drug Deliv Rev 153:87-108

68. Yadav AK, Gupta U, Sharma R (eds) (2020) Nano drug delivery strategies for the treatment of cancers. Academic Press, pp 245-273

69. Dolatabadi JEN, Valizadeh H, Hamishehkar H (2015) Solid lipid nanoparticles as efficient drug and gene delivery systems: recent breakthroughs. Adv Pharm Bull 5(2):151-159

70. Liu J, Hu W, Chen H et al (2007) Isotretinoin-loaded solid lipid nanoparticles with skin targeting for topical delivery. Int J Pharm 328(2):191-195
71. Muller RH, Radtke M, Wissing SA (2002) Solid lipid nanoparticles (SLN) and nanostructured lipid carriers (NLC) in cosmetic and dermatological preparations. Adv Drug Deliv Rev Suppl 1(35):S131-S155

72. Rostami E, Kashanian S, Azandaryani AH et al (2014) Drug targeting using solid lipid nanoparticles. Chem Phys Lipids 181:56-61

73. Fleury S, Vianna Lopez RF (2011) Chapter 11, Topical administration of anticancer drugs for skin cancer treatment. In: Skin cancers - risk factors, prevention and therapy. Intech Press, London, pp 243-272

74. Tupal A, Sabzichi M, Ramezani F et al (2016) Dermal delivery of doxorubicin-loaded solid lipid nanoparticles for the treatment of skin cancer. J Microencapsul 33(4):372-380

75. Cassano R, Mellace S, Marrelli M et al (2017) a-Tocopheryl linolenate solid lipid nanoparticles for the encapsulation, protection, and release of the omega-3 polyunsaturated fatty acid: in vitro anti-melanoma activity evaluation. Colloids Surf B Biointerfaces 151:128-133

76. Geetha T, Kapila M, Prakash O et al (2015) Sesamol-loaded solid lipid nanoparticles for treatment of skin cancer. J Drug Target 23(2):159-169

77. Gupta T, Singh J, Kaur S, Sandhu S, Singh G, Kaur IP (2020) Enhancing bioavailability and stability of curcumin using solid lipid nanoparticles (CLEN): a covenant for its effectiveness. Front Bioeng Biotechnol 8:879

78. Bayón-Cordero L, Alkorta I, Arana L (2019) Application of solid lipid nanoparticles to improve the efficiency of anticancer drugs. Nanomaterials 9(3):474

79. Pople P, Singh K (2011) Development and evaluation of colloidal modified nanolipid carrier: application to topical delivery of tacrolimus. Eur J Pharm Biopharm 79:82-94

80. Almousallam M, Moia C, Zhu H (2015) Development of nanostructured lipid carrier for dacarbazine delivery. Int Nano Lett 5(4):241-248

81. Iqbal B, Ali J, Ganguli M et al (2019) Silymarin-loaded nanostructured lipid carrier gel for the treatment of skin cancer. Nanomedicine 14(9):1077-1093

82. Zhao J, Piao X, Shi X et al (2016) Podophyllotoxin-loaded nanostructured lipid carriers for skin targeting: in vitro and in vivo studies. Molecules 21:1549

83. Rapalli VK, Kaul V, Waghule T et al (2020) Curcumin loaded nanostructured lipid carriers for enhanced skin retained topical delivery: optimization, scale-up, in-vitro characterization and assessment of ex-vivo skin deposition. Eur J Pharm Sci 152:105438. https://doi.org/10.1016/j.ejps. 2020.105438

84. Malta R, Loureiro JB, Costa P, Sousa E, Pinto M, Saraiva L, Amaral MH (2021) Development of lipid nanoparticles containing the xanthone LEM2 for topical treatment of melanoma. J Drug Deliv Sci Technol 61:102226

85. Zhang L, Zhang N (2013) How nanotechnology can enhance docetaxeltherapy. Int J Nanomed 8:2927-2941

86. Abbasi E, Aval SF, Akbarzadeh A et al (2014) Dendrimers: synthesis, applications, and properties. Nanoscale Res Lett 9(1):247

87. Nazir S, Hussain T, Ayub A et al (2014) Nanomaterials in combating cancer: therapeutic applications and developments. Nanomed Nanotechnol Biol Med 10(1):19-34

88. Dianzani C, Zara GP, Maina G et al (2014) Drug delivery nanoparticles in skin cancers. BioMed Res Int 2014:1-13

89. Jiang G, Li R, Tang J, Ma Y, Hou X, Yang C, Guo W, Xin Y, Liu Y (2017) Formulation of temozolomide-loaded nanoparticles and their targeting potential to melanoma cells. Oncol Rep 37(2):995-1001

90. Yuan F, Leunig M, Huang K et al (1994) Microvascular permeability and interstitial penetration of sterically stabilized (stealth) liposomes in a human tumor xenograft. Cancer Res 54(13):3352-3356

91. Torchilin VP (2005) Recent advances with liposomes as pharmaceutical carriers. Nat Rev Drug Discov 4(2):145-160

92. Golombek SK, May JN, Theek B, Appold L, Drude N, Kiessling F, Lammers T (2018) Tumor targeting via EPR: strategies to enhance patient responses. Adv Drug Deliv Rev 130:17-38

93. Woźniak M, Nowak M, Lazebna A, Więcek K, Jabłońska I, Szpadel K, Grzeszczak A, Gubernator J, Ziółkowski P (2021) The comparison of in vitro photosensitizing efficacy of curcumin-loaded liposomes following photodynamic therapy on melanoma MUG-Mel2, squamous cell 
carcinoma SCC-25, and normal keratinocyte HaCaT cells. Pharmaceuticals 14(4):374

94. Slingerland M, Guchelaar H, Gelderblom H (2012) Liposomal drug formulations in cancer therapy: 15 years along the road. Drug Discov Today 17(3-4):160-166

95. Touitou E, Dayan N, Bergelson L et al (2000) Ethosomes—novel vesicular carriers for enhanced delivery: characterization and skin penetration properties. J Control Release 65(3):403-418

96. Cristiano MC, Froiio F, Spaccapelo R et al (2019) Sulforaphane-loaded ultradeformable vesicles as a potential natural nanomedicine for the treatment of skin cancer diseases. Pharmaceutics 12:6

97. Nayak D, Thathapudi NC, Ashe S, Nayak B (2021) Bioengineered ethosomes encapsulating AgNPs and Tasar silk sericin proteins for non melanoma skin carcinoma (NMSC) as an alternative therapeutics. Int J Pharm 596:120265

98. Cevc G, Schätzlein A, Blume G (1995) Transdermal drug carriers: Basic properties, optimization and transfer efficiency in the case of epicutaneously applied peptides. J Control Release 36(1):3-16

99. Chen M, Shamim MA, Shahid A et al (2020) Topical delivery of carvedilol loaded nano-transfersomes for skin cancer chemoprevention. Pharmaceutics 12(12):1151

100. Ganta S, Talekar M, Singh A et al (2014) Nanoemulsions in translational research-opportunities and challenges in targeted cancer therapy. AAPS PharmSciTech 15(3):694-708

101. McClements DJ (2012) Nanoemulsions versus microemulsions: terminology, differences, and similarities. Soft Matter 8:1719-1729

102. Tiwari S, Tan Y-M, Amiji M (2006) Preparation and in vitro characterization of multifunctional nanoemulsions for simultaneous MR imaging and targeted drug delivery. J Biomed Nanotechnol 2(3):217-224

103. Sanchez-Lopez E, Guerra M, Dias-Ferreira J et al (2019) Current applications of nanoemulsions in cancer therapeutics. Nanomaterials 9(6):821-825

104. Shakeel F, Haq N, Al-Dhfyan A et al (2015) Chemoprevention of skin cancer using low HLB surfactant nanoemulsion of 5-fluorouracil: a preliminary study. Drug Deliv 22(4):573-580

105. Tagne JB, Kakumanu S, Nicolosi RJ (2008) Nanoemulsion preparations of the anticancer drug dacarbazine significantly increase its efficacy in a xenograft mouse melanoma model. Mol Pharm 6:1055-1063

106. Adhikari M, Kaushik N, Ghimire B et al (2019) Cold atmospheric plasma and silymarin nanoemulsion synergistically inhibits human melanoma tumorigenesis via targeting HGF/c-MET downstream pathway. Cell Commun Signal 17(1):1-14

107. Anuchapreeda S, Fukumori Y, Okonogi S et al (2012) Preparation of lipid nanoemulsions incorporating curcumin for cancer therapy. J Nanotechnol 2012:1-11

108. Kazemi M, Mohammadifar M, Aghadavoud E et al (2020) Deep skin wound healing potential of lavender essential oil and licorice extract in a nanoemulsion form: Biochemical, histopathological and gene expression evidences. J Tissue Viability 29(2):116-124

109. Giacone DV, Dartora VF, de Matos JK et al (2020) Effect of nanoemulsion modification with chitosan and sodium alginate on the topical delivery and efficacy of the cytotoxic agent piplartine in $2 \mathrm{D}$ and $3 \mathrm{D}$ skin cancer models. Int J Biol Macromol 15(165):1055-1065

110. Yang G, Wang J, Wang Y et al (2015) An implantable active-targeting micelle-in-nanofiber device for efficient and safe cancer therapy. ACS Nano 9(2):1161-1174

111. Rengifo AFC, Stefanes NM, Toigo J et al (2019) PEO-chitosan nanofibers containing carboxymethyl-hexanoyl chitosan/dodecyl sulfate nanoparticles loaded with pyrazoline for skin cancer treatment. Eur Polym J 119:335-343

112. Balashanmugam P, Sucharithra G, Agnes Mary S, Tamil SA (2020) Efficacy of biopolymeric PVA-AuNPs and PCL-Curcumin loaded electrospun nanofibers and their anticancer activity against A431 skin cancer cell line. Mater Today Commun 25:101276
113. Calienni MN, Febres-Molina C, Llovera RE et al (2019) Nanoformulation for potential topical delivery of Vismodegib in skin cancer treatment. Int J Pharm 565:108-122

114. Jang EJ, Choi WR, Kim SY et al (2017) 2-hydroxyoleic acid-inserted liposomes as a multifunctional carrier of anticancer drugs. Drug Deliv 24(1):1587-1597

115. Yeo DC, Wiraja C, Paller AS et al (2018) Abnormal scar identification with spherical-nucleic-acid technology. Nat Biomed Eng 2:227-238

116. Zheng D, Giljohann DA, Chen DL et al (2012) Topical delivery of siRNAbased spherical nucleic acid nanoparticle conjugates for gene regulation. Proc Natl Acad Sci 109(30):11975-11980

117. Nemati H, Ghahramani MH, Faridi-Majidi R et al (2017) UsingsiRNAbased spherical nucleic acid nanoparticle conjugates for gene regulation in psoriasis. J Control Release 268:259-268

118. Li J, Fan C, Pei H et al (2013) Smart drug delivery nanocarriers with selfassembled DNA nanostructures. Adv Mat 25(32):4386-4396

119. Douglas SM, Dietz H, Liedl T et al (2009) Self-assembly of DNA into nanoscale three-dimensional shapes. Nature 459(7245):414-418

120. Wiraja C, Zhu Y, Lio DCS et al (2019) Framework nucleic acids as programmable carrier for transdermal drug delivery. Nat Commun 10(1):1-12

121. Wiraja C, Yeo DC, Xu C (2019) Framework nucleic acids: a paradigm shift in transdermal drug delivery. SLAS Technol 24(5):531-532

122. Chen M, Kumar S, Anselmo AC et al (2015) Topical delivery of Cyclosporine A into the skin using SPACE-peptide. J Control Release 199:190-197

123. Gautam A, Nanda JS, Samuel JS et al (2016) Topical delivery of protein and peptide using novel cell penetrating peptide IMT-P8. Sci Rep 6:1-13

124. Tong R, Hemmati HD, Langer R et al (2012) Photoswitchable nanoparticles for triggered tissuepenetration and drug delivery. J Am Chem Soc 134(21):8848-8855

125. Tong R, Chiang HH, Kohane DS (2013) Photoswitchable nanoparticles for in vivo cancer chemotherapy. Proc Natl Acad Sci USA 110(47):19048-19053

126. Lin CT, Lin IC, Sung SY et al (2016) Dual-targeted photopenetrative delivery of multiple micelles/hydrophobic drugs by a Nanopea for enhanced tumor therapy. Adv Funct Mater 26(23):4169-4179

127. Wang B, Zhai Y, Shi J et al (2017) Simultaneously overcome tumor vascular endothelium and extracellular matrix barriers via a non-destructive size-controlled nanomedicine. J Control Release 268:225-236

128. Kong SD, Zhang W, Lee JH et al (2010) Magnetically vectored nanocapsules for tumor penetration and remotely switchable on-demand drug release. NanoLett 10(12):5088-5092

129. Soheilian R, Choi YS, David AE et al (2015) Toward accumulation of magnetic nanoparticles into tissues of small porosity. Langmuir 31(30):8267-8274

130. Li HJ, Du JZ, Liu J et al (2016) Smart superstructures with ultrahigh $\mathrm{pH}$-sensitivity for targeting acidic tumor microenvironment: instantaneous size switching and improved tumor penetration. ACS Nano 10(7):6753-6761

131. Van Straten D, Mashayekhi V, De Bruijn HS et al (2017) Oncologic photodynamic therapy: basic principles, current clinical status and future directions. Cancers 9:19

132. Goto PL, Siqueira-Moura MP, Tedesco AC (2017) Application of aluminum chloride phthalocyanineloaded solid lipid nanoparticles for photodynamic inactivation of melanoma cells. Int J Pharm 518(1-2):228-241

133. Rady M, Gomaa I, Afifi N et al (2018) Dermal delivery of Fe-chlorophyllin via ultradeformable nanovesicles for photodynamic therapy in melanoma animal model. Int J Pharm 548(1):480-490

134. Keyal U, Bhatta AK, Zhang G et al (2019) Present and future perspectives of photodynamic therapy for cutaneous squamous cell carcinoma. J Am Acad Dermatol 80(3):765-773 
135. Elisa G, Andrea G, Marco B et al (2019) Keratin nanoparticles co-delivering Docetaxel and Chlorin e6 promote synergic interaction between chemo- and photo-dynamic therapies. J Photochem Photobiol B 199:1-13

136. Prasad C, Banerjee R (2019) Ultrasound triggered spatiotemporal delivery of Topotecan and Curcumin as combination therapy for cancer. J Pharmacol ExpTher 370(3):876-893

137. Hao Y, Dong M, Zhang T et al (2017) Novel approach of using nearinfrared responsive PEGylated gold nanorod coated poly(L-lactide) microneedles to enhance the antitumor efficiency of Docetaxel-loaded MPEG-PDLLA Micelles for treating an A431 tumor. ACS Appl Mater Interfaces 9(18):15317-15327

138. Tham HP, Xu K, Lim WQ et al (2018) Microneedle-assisted topical delivery of photodynamically active mesoporous formulation for combination therapy of deep-seated melanoma. ACS Nano 12(12):11936-11948

139. Lan X, She J, Lin DA et al (2018) Microneedle-mediated delivery of lipidcoated cisplatin nanoparticles for efficient and safe cancer therapy. ACS Appl Mater Interfaces 10(39):33060-33069

140. Yao Q, Choi JH, Dai Z et al (2017) Improving tumor specificity and anticancer activity of Dasatinib by dual-targeted polymeric micelles. ACS Appl Mater Interfaces 9(42):36642-36654

\section{Publisher's Note}

Springer Nature remains neutral with regard to jurisdictional claims in published maps and institutional affiliations.

\section{Submit your manuscript to a SpringerOpen ${ }^{\circ}$ journal and benefit from:}

- Convenient online submission

- Rigorous peer review

- Open access: articles freely available online

- High visibility within the field

- Retaining the copyright to your article

Submit your next manuscript at $\boldsymbol{\nabla}$ springeropen.com 